\title{
Mound Laboratory Isotopic Power Fuels Programs: July-September 1973
}

November 21, 1973

\section{MOUND LABORATORY}

Miamisburg, Ohio

operated by

Monsanto

MONSANTO RESEARCH CORPORATION a subsidiary of Monsanto Company for the

U. S. ATOMIC ENERGY COMMISSION

U. S. Government Contract No. AT-33-1-GEN-53 


\section{DISCLAIMER}

This report was prepared as an account of work sponsored by an agency of the United States Government. Neither the United States Government nor any agency Thereof, nor any of their employees, makes any warranty, express or implied, or assumes any legal liability or responsibility for the accuracy, completeness, or usefulness of any information, apparatus, product, or process disclosed, or represents that its use would not infringe privately owned rights. Reference herein to any specific commercial product, process, or service by trade name, trademark, manufacturer, or otherwise does not necessarily constitute or imply its endorsement, recommendation, or favoring by the United States Government or any agency thereof. The views and opinions of authors expressed herein do not necessarily state or reflect those of the United States Government or any agency thereof. 


\section{DISCLAIMER}

Portions of this document may be illegible in electronic image products. Images are produced from the best available original document. 


\title{
Mound Laboratory Isotopic Power Fuels Programs: July-September 1973
}

Issued: November 21, 1973

\section{NOTICE}

\begin{abstract}
This report was prepared as an account of work sponsored by the United States Government. Neither the United States nor the United States Atomic Energy Com mission, nor any of their employees, nor any of the ir contractors, subcontractors, or their employees, makes, any warranty, express or implied, or assumes any legol liability or responsibility for the accuracy, completeness or usefulness of any information, appqatus, product or process disclosed, or represents that its use would not infringe privately owned rights.
\end{abstract}

PRINTED IN THE UNITED STATES OF AMERICA

Avallable from

National Technical Information Service

U. S. Department of Commerce

5285 Port Royal Road

Springfield, Virginia 22151

Price: Printed Copy $\$ 4.00$ Microfiche $\$ 1.45$

\section{MONSANTO RESEARCH CORPORATION}

A Subsidiary of Monsanto Company

\section{MOUND LABORATORY}

Miamisburg, Ohio

45342

operated for

\section{UNITED STATES ATOMIC ENERGY COMMISSION}

US Government Contract No AT-33-1-GEN-53 


\section{Foreword}

This report presents the technological achievements of Mound Laboratory in its isotopic fuels programs during the past three months. The separate reports compiled here represent the work of the following sections of the Nuclear Operations Department (Director W. T. Cave): Heat Sources (Manager D. P. Ke1ly), and Technology Applications \& Development (Manager R. E. Valié).

This work is supported by the AEC Division of Space Nuclear Systems.

Summaries of a11 sections are compiled at the front of this report. Brief introductions to the work are included with each section.

Previous reports in this series are:

MLM - 1905

MLM- 2014

MLM-1945

MLM-1983

MLM- 2040

MLM-2080 


\section{Table of Contents}

PLUTONIUM-238 FUELS

$\underline{\text { Page }}$

FUEL PREPARATION

Effect of Lower Pressing Temperatures on Pressed Plutonium Oxide (PPO) Spheres . . . . . . . . . . . . . .

Plutonium-238 dioxide feed materia1 that was sintered to a maximum of on $1 y 900^{\circ} \mathrm{C}$ was pressed under otherwise normal conditions into a Multihundred Watt (MHW) type fuel sphere. This pressing resulted in a sphere with near-perfect surface texture. The surface was bright and totally free of any visible cracks. However, upon subjection to the normal $1500^{\circ} \mathrm{C}$ vacuum heat treatment, the sphere cracked severely.

FUEL CHARACTERIZATION

Microstructural Analyses of PPO Spheres . . . . . . . . . . . 7

Selected areas of MHW PPO spheres were metallographically examined to see if any general observations could be made regarding the spheres. These examinations showed that the spheres were not uniform in microstructure. They possessed nonuniform grain size and porosity distribution. Spheres exposed to high-temperature heat treatments also were nonuniform in microstructure.

Thermal Stress Analyses . . . . . . . . . . . . . . 14

Calculations were performed to determine the stresses that appear in MHW PPO spheres due to temperature gradients. Thermal shock analyses were also performed. The data obtained as a result of these analyses were used in establishing a controlled heating and cooling cycle for the $1500^{\circ} \mathrm{C}$, 1 -hr outgassing process for development and production spheres. 
A Quadrupole Mass Spectrometer Capable of Evolved Gas

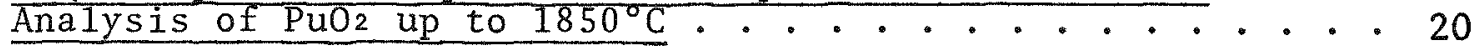

A residual gas analysis system utilizing a quadrupole mass spectrometer was installed in an alpha glovebox. The installation and cold check-out of the system are essentially completed. Several nonradioactive samples and standards were analyzed to establish the sensitivity and to calibrate the instrument.

Plutonium in Environmental Waters . . . . . . . . . . . . 21

A method of estimating the concentration of pentavalent plutonium in environmental waters is proposed.

\section{CAPSULE MATERIALS}

EXAMINATION OF IRIDIUM HEMISHELLS . . . . . . . . . . . . 24

Samples of iridium hemishells were examined using the quadrupole mass spectrometer and both transmission and scanning electron microscopy. These examinations were performed in an attempt to better identify the nature of the iridium being used in the Multihundred Watt Heat Source Program. 


\title{
Plutonium-238 Fuels
}

\author{
FUEL PREPARATION
}

Effect of Lower Pressing Temperature on Pressed Plutonium Oxide (PPO) Spheres The effect of lowering the pressing temperature on vacuum-hotpressed PPO spheres is being evaluated. The lower temperature should increase the compatibility of the $\mathrm{PuO}_{2}$ fuel with the graphite punch and die assembly and, thus, lower the carbon impurity and improve the appearance (texture) of the produced sphere. The lowering of the carbon content in the as-pressed sphere could lead to dropping of the necessity of oxygen-16 treatment, which is presently used to remove carbon impurity from the surface of the sphere.

Elimination of the post-pressing oxygen-16 treatment would result in a significant savings in process time. In addition, if the pressing temperature could be lowered significantly without affecting the quality of the produced sphere, there might be a chance of either reusing the graphite punch and die assembly or using another material that would be usable for several pressings for the punch and die assembly. However, at this time no other such material of reasonable cost is immediately apparent.

Norma11y, PPO spheres are pressed at $1400-1480^{\circ} \mathrm{C}$, using $300-25001 \mathrm{~b}$ force from hydroxide-precipitated feed (previously sintered to $1200-1250^{\circ} \mathrm{C}$ ). From experience, it was learned that feed material sintered to on $1 y 900^{\circ} \mathrm{C}$ pressed considerably easier; i.e., the punches closed out at much lower temperature. Therefore, a sphere was pressed from ${ }^{23}{ }^{3} \mathrm{PuO}_{2}$ feed material that was sintered at $900^{\circ} \mathrm{C}$. Although this material was considerably easier to press than $1250^{\circ} \mathrm{C}$ feed material, the punches did not completely close even at $1150^{\circ} \mathrm{C}$ and $16,000 \mathrm{lb}$ force. The polar and equatorial diameters of this sphere were 1.480 and 1.471 in., respectively. These diameters correspond to a density range of 79.5 to $81.1 \%$ of theoretical. The slightly high, although within MHW specification, polar diameter resulted from incomplete closing of the punches and thus, yielded a density slightly lower than the normally obtained $82 \%$. The sphere's surface was bright and shiny (Figure 1) and was completely void of visual imperfections such as small cracks.

Usual1y, a PPO sphere develops very small surface cracks within 1 hr after removal from the die. This sphere, however, did not develop any visible surface cracks after standing for four days at ambient temperature. 


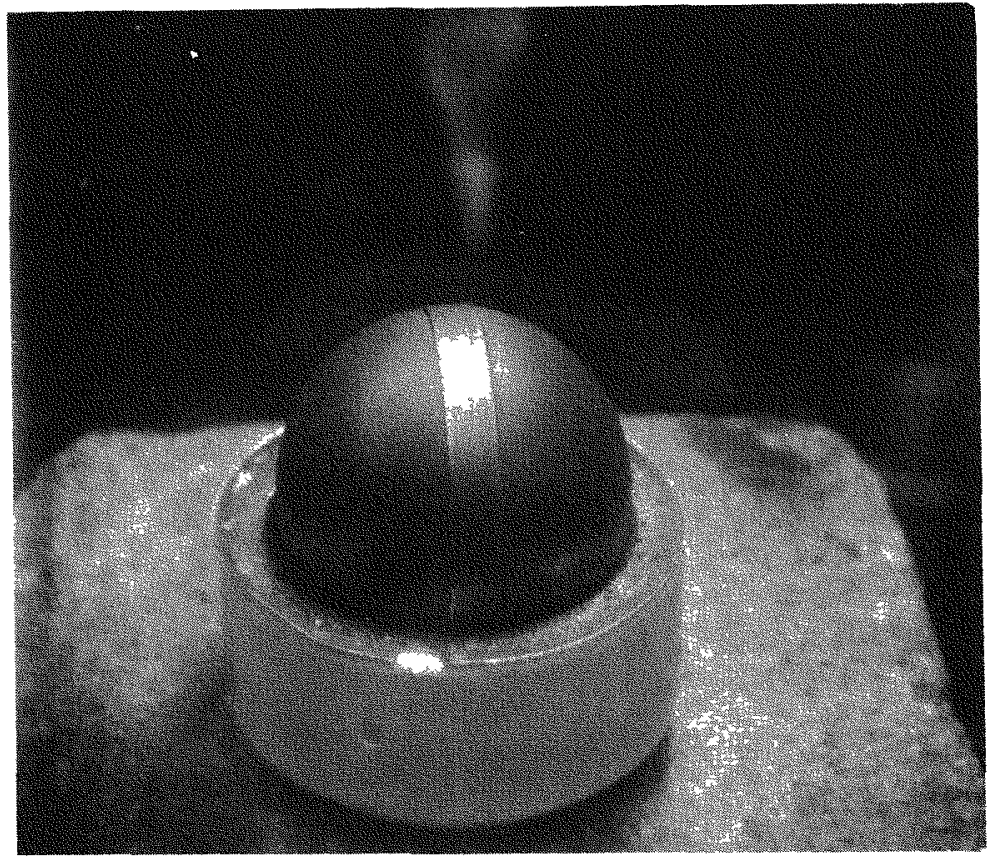

FIGURE $1-{ }^{238} \mathrm{Pu}^{16} \mathrm{O}_{2}$ sphere hot pressed at $1150^{\circ} \mathrm{C}$ using $16,000 \mathrm{lb}$ force.

Inspection of the graphite punch cavity after pressing revealed that very little reaction had occurred with the ${ }^{23}{ }^{8} \mathrm{PuO}_{2}$. However, one of the knife edges was broken in several places.

The sphere was subsequently subjected to the normal vacuum outgassing at $1500^{\circ} \mathrm{C}$. The sphere cracked severely during this procedure. A decrease in the equatorial diameter of 0.006 in. to 1.465 in. resulted from the heat treatment. It was not possible to obtain a meaningful measurement of the polar diameter because of the severe cracking in the polar region. If the polar diameter would have decreased by an equivalent amount (0.006-0.009 in.) without cracking, a near ideal sphere would have resulted. However, it is entirely possible and even probable that the 1ack of cracks (or perfection) in the as-pressed sphere as stress relievers was the very reason for the sphere's lack of stability to thermal shock. (W. D. Pardieck, W. A. Zanotelli and R. R. Jaeger) 


\section{FUEL CHARACTERIZATION}

Microstructural Analysis of PPO Spheres Samples from five PPO spheres were cross-sectioned and examined. Data presented in Table 1 indicate that the porosity distribution and grain size are not uniform across a sphere. This is also true for spheres exposed to $1500^{\circ} \mathrm{C}$ heat treatment for long periods of time. Figures 2 through 6 show photomicrographs of metallographic samples taken from spheres exposed to different thermal environments.

Figure 2 represents the cross-sectional view of sphere A. The various micrographs were taken from the approximate areas illustrated on the sphere in the figure. The samples from sphere A show that: 1) grain size is fairly uniform; 2) porosity is not uniform and the nature of the porosity is different throughout the sphere (large areas of interconnected porosity of irregular shape, areas of isolated porosity between particles, and isolated spherical porosity in the particles); 3) microcracks are already prevalent throughout the matrix of the sphere with the larger ones concentrated in the interior of the sphere.

Since resistance to thermal shock and stress depends on a combination of strength, elasticity, thermal conductivity, thermal expansion, and Poisson's ratio, and since all of these are affected by porosity, the relative magnitude of these properties cannot be anticipated with much confidence in samples such as that shown in Figure 2. Calculated numerical values ${ }^{1}$ must be tempered with experimental evidence. The fact that interior cracks are already present in the sphere after pressing implies that an analysis of crack propagation and healing is also required to fully characterize the thermal behavior of PPO spheres.

Figures 3 (sphere B) and 4 (sphere E) show photomicrographs of spheres subjected to different thermal environments. Both spheres contain mixed porosity. Figures 5 (sphere G) and 6 (sphere H) show cross-sections of spheres that have been exposed to a thermal environment of $1500^{\circ} \mathrm{C}$ for $18 \mathrm{hr}$. While both spheres appear more uniform than spheres exposed to less severe thermal environments, they do have different kinds of porosity present in their microstructure as well as microcracks located in the most dense equatorial regions.

If the data presented in Table 1 are compared with the photomicrographs of the various spheres, several observations can be made. These are: 1) Microcracks are present inside some spheres even in the as-pressed condition; 2) For spheres subjected to additional thermal environments after pressing the grain size distribution is not uniform. Larger grains appear in the core region while smaller grains are present near the surface; 3) No consistent relationship between the thermal environment and grain growth was apparent. Some spheres exposed to lower temperature exhibited larger grain sizes than present in spheres exposed to higher temperatures. 4) The spheres appear to have a density gradient opposite the thermal gradient; $i . e .$, the sphere core appears less dense than the outer regions. Whether or not this density gradient is geometrically uniform and consistent remains equivocal until completion of studies using Classimet equipment on much larger samples. 
Table 1

POROSITY AND GRAIN SIZE DATA AVAILABLE ON EXAMINED PPO SPHERES

\begin{tabular}{|c|c|c|c|c|c|c|c|c|c|}
\hline \multirow{2}{*}{ Sphere } & \multirow{2}{*}{$\begin{array}{l}\text { Maximum Thermal } \\
\text { History After } \\
\text { Pressing at } 1480^{\circ} \mathrm{C} \\
\end{array}$} & \multirow{2}{*}{\multicolumn{2}{|c|}{$\begin{array}{l}\text { Location: Pole } \\
\begin{array}{c}\text { Porosity } \\
\left(\frac{8}{0}\right)\end{array}-(\mu \mathrm{m}) \\
\end{array}$}} & \multicolumn{2}{|c|}{ Equator } & \multicolumn{2}{|c|}{ Mid-Radius } & \multicolumn{2}{|c|}{ Core } \\
\hline & & & & $\begin{array}{l}\text { Porosity } \\
(\%)\end{array}$ & $\begin{array}{l}\text { Grain Size } \\
(\mu \mathrm{m})\end{array}$ & $\begin{array}{l}\text { Porosity } \\
\left(\frac{0}{0}\right) \\
\end{array}$ & $\begin{array}{c}\text { Grain Size } \\
(\mu \mathrm{m})\end{array}$ & $\begin{array}{c}\text { Porosity } \\
\left(\begin{array}{l}0 \\
0\end{array}\right) \\
\end{array}$ & $\begin{array}{c}\text { Grain Size } \\
(\mu \mathrm{m})\end{array}$ \\
\hline A & As Pressed & 33.0 & 10.0 & 23.1 & 7.5 & 29.8 & 10.0 & $\mathrm{~N} / \mathrm{A}$ & $\mathrm{N} / \mathrm{A}$ \\
\hline B & ${ }^{16} \mathrm{O}_{2}$ exchange at $\sim 675^{\circ} \mathrm{C}$ & 16.8 & N/A & 15.6 & N/A & 26.0 & N/A & 29.2 & N/A \\
\hline $\mathrm{C}$ & ${ }^{16} \mathrm{O}_{2}$ exchange at $\sim 740^{\circ} \mathrm{C}$ & 20.0 & 25.0 & 7.0 & 20.0 & 23.7 & 30.0 & 20.5 & 40.0 \\
\hline $\mathrm{D}$ & $\begin{array}{l}{ }^{16} \mathrm{O}_{2} \text { exchange at } \sim 675^{\circ} \mathrm{C} \\
\text { Outgassed } 30 \mathrm{~min} \text { at } 1200^{\circ} \mathrm{C}\end{array}$ & 11.2 & 6.0 & 11.1 & 80.0 & N/A & $\mathrm{N} / \mathrm{A}$ & 24.4 & 80.0 \\
\hline $\mathrm{E}$ & $\begin{array}{l}{ }^{16} \mathrm{O}_{2} \text { exchange at } \sim 675^{\circ} \mathrm{C} \\
\text { outgassed } 30 \text { min at } 1500^{\circ} \mathrm{C}\end{array}$ & 14.7 & 7.5 & 12.6 & 12.5 & N/A & N/A & 21.3 & 35.10 \\
\hline F & $\begin{array}{l}{ }^{16} \mathrm{O}_{2} \text { exchange at } \sim 750^{\circ} \mathrm{C} \\
\text { Outgassed } 1 \mathrm{hr} \text { at } 1500^{\circ} \mathrm{C}\end{array}$ & 14.8 & 26.4 & 10.5 & 34.0 & 22.2 & 31.5 & 23.0 & 47.2 \\
\hline G & $\begin{array}{l}{ }^{16} \mathrm{O}_{2} \text { exchange at }-665^{\circ} \mathrm{C} \\
\text { Outgassed } 1 \mathrm{hr} \text { at } 1200^{\circ} \mathrm{C} \\
\text { Encapsulated }-18 \mathrm{hr} \text { at } 1500^{\circ} \mathrm{C}\end{array}$ & 20.0 & 80.0 & 16.0 & 60.0 & 19.0 & 90.0 & 21.0 & 100.0 \\
\hline H & $\begin{array}{l}{ }^{16} \mathrm{O}_{2} \text { exchange at } \sim 665^{\circ} \mathrm{C} \\
\text { Outgassed } 1 \mathrm{hr} \text { at } 1200^{\circ} \mathrm{C} \\
\text { Encapsulated }-18 \text { hr at } 1500^{\circ} \mathrm{C}\end{array}$ & 12.5 & $\mathrm{~N} / \mathrm{A}$ & 11.4 & $\mathrm{~N} / \mathrm{A}$ & 23.0 & $\mathrm{~N} / \mathrm{A}$ & N/A & $\mathrm{N} / \mathrm{A}$ \\
\hline
\end{tabular}

N/A - Data not available at the present time. 

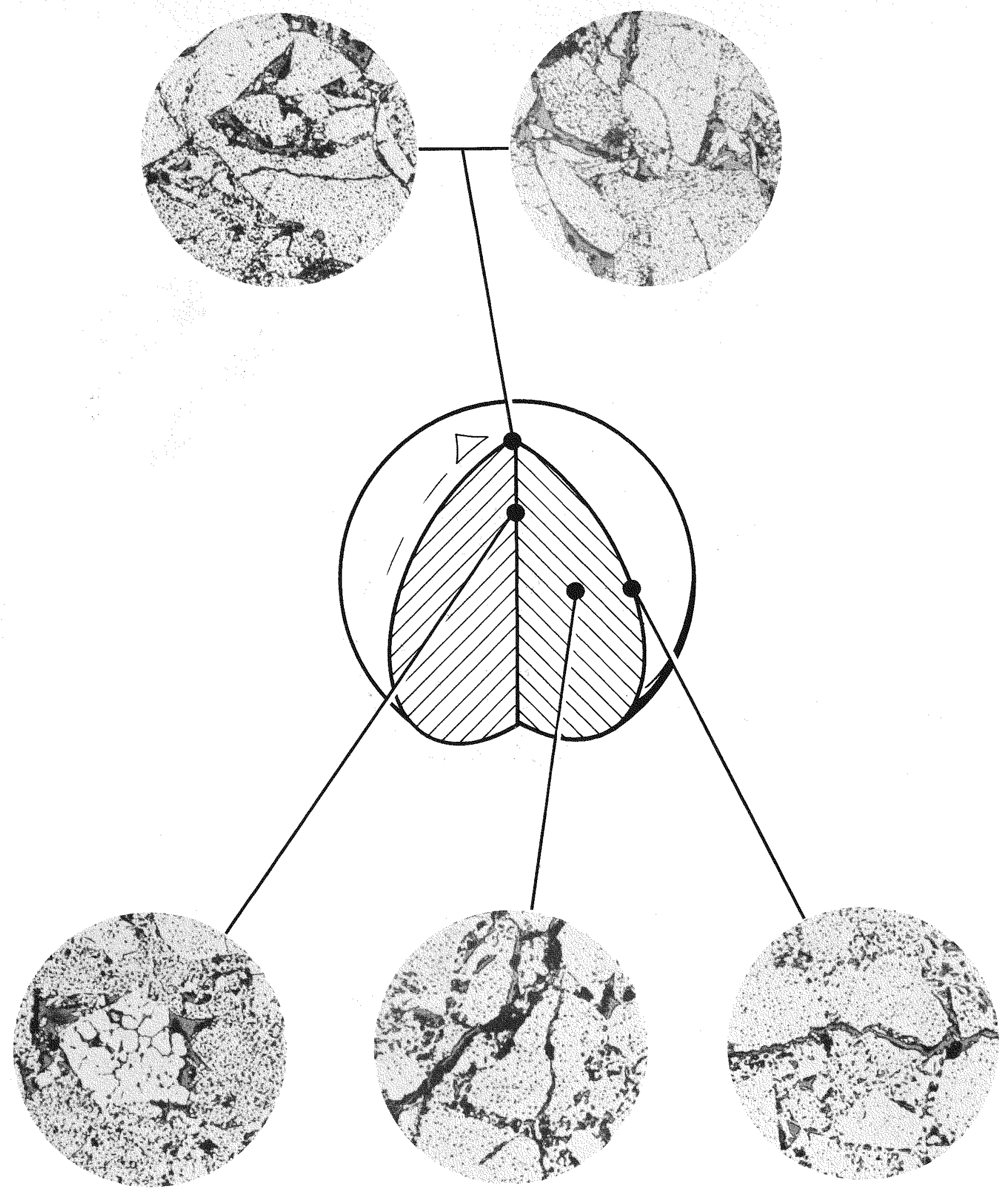

FIGURE 2 - PPO sphere A - as pressed. (125X) 


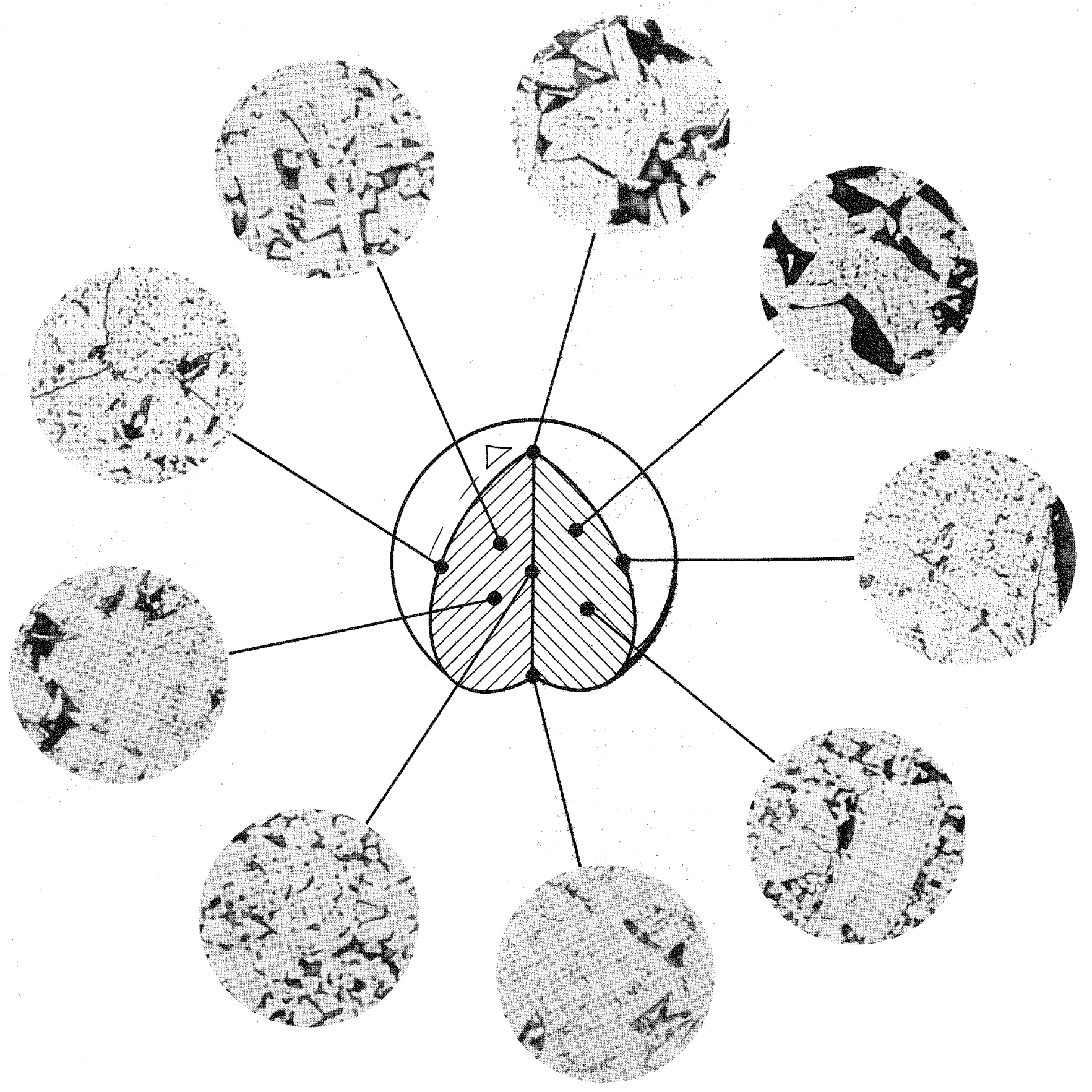

FIGURE 3 - PPO sphere B - oxygen exchanged at $675^{\circ} \mathrm{C}$.

(125X) 


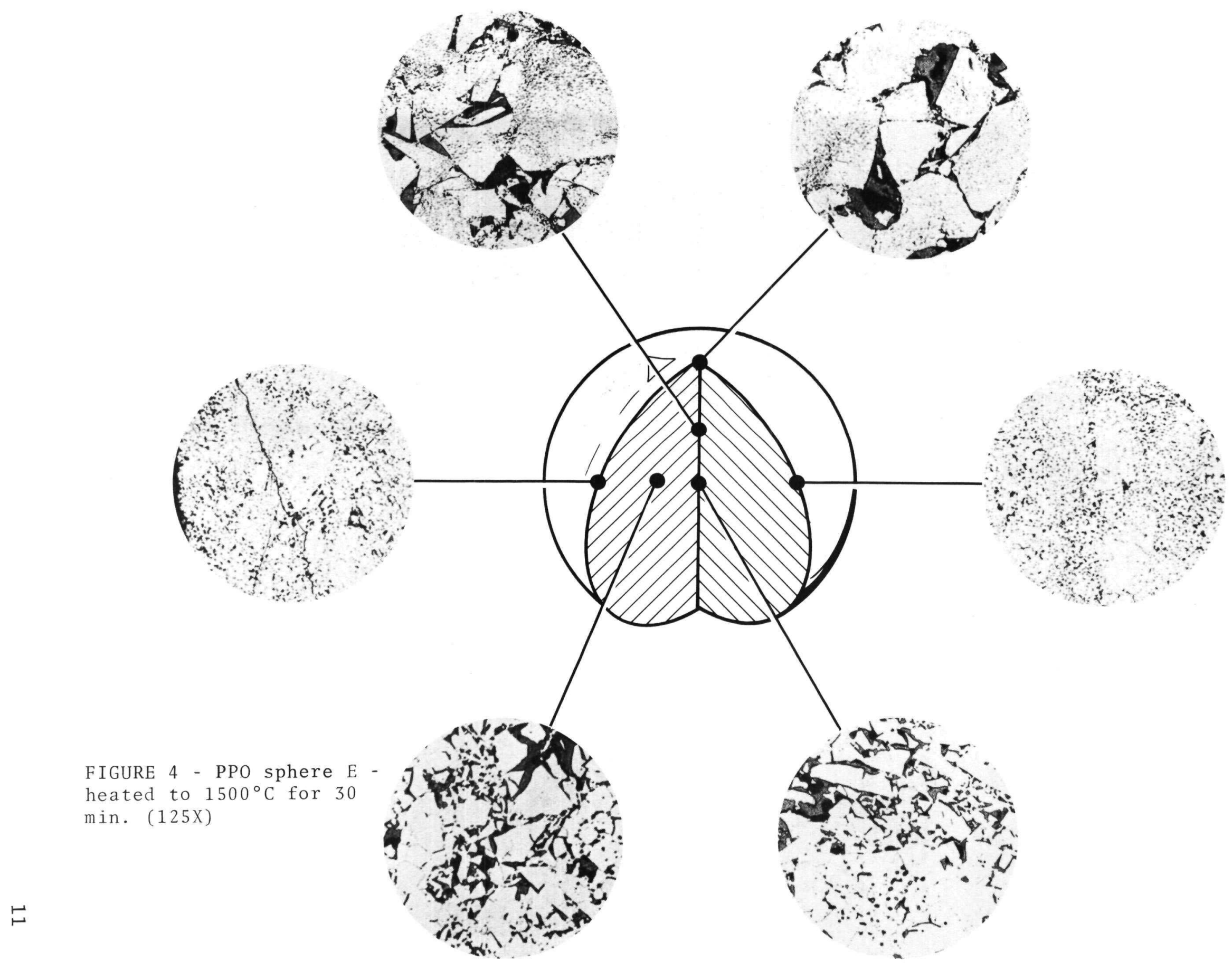




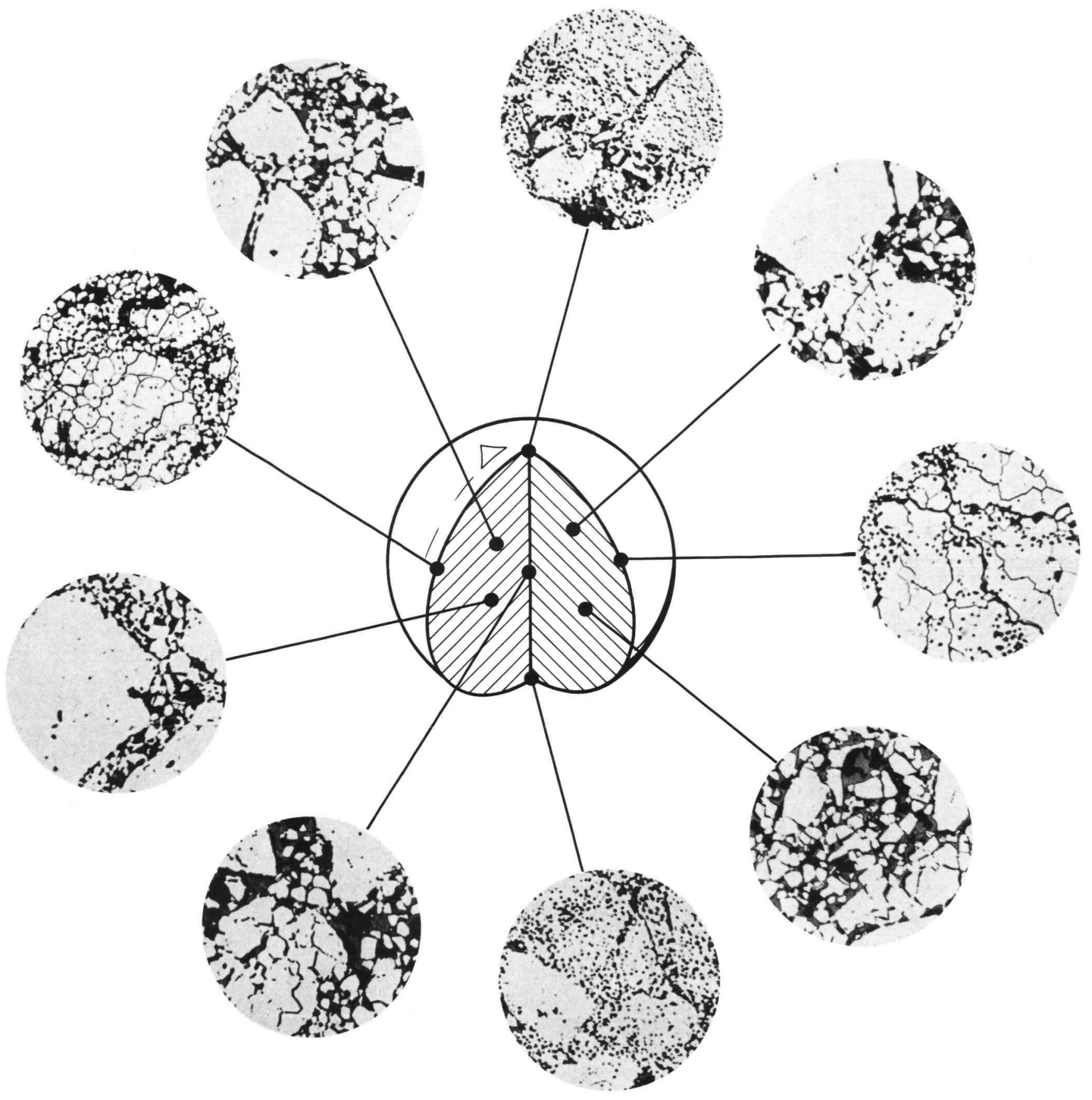

FIGURE 5 - PPO sphere $\mathrm{G}$ - heat treated at $1500^{\circ} \mathrm{C}$ for $18 \mathrm{hr}$.
$(125 \mathrm{X})$ 


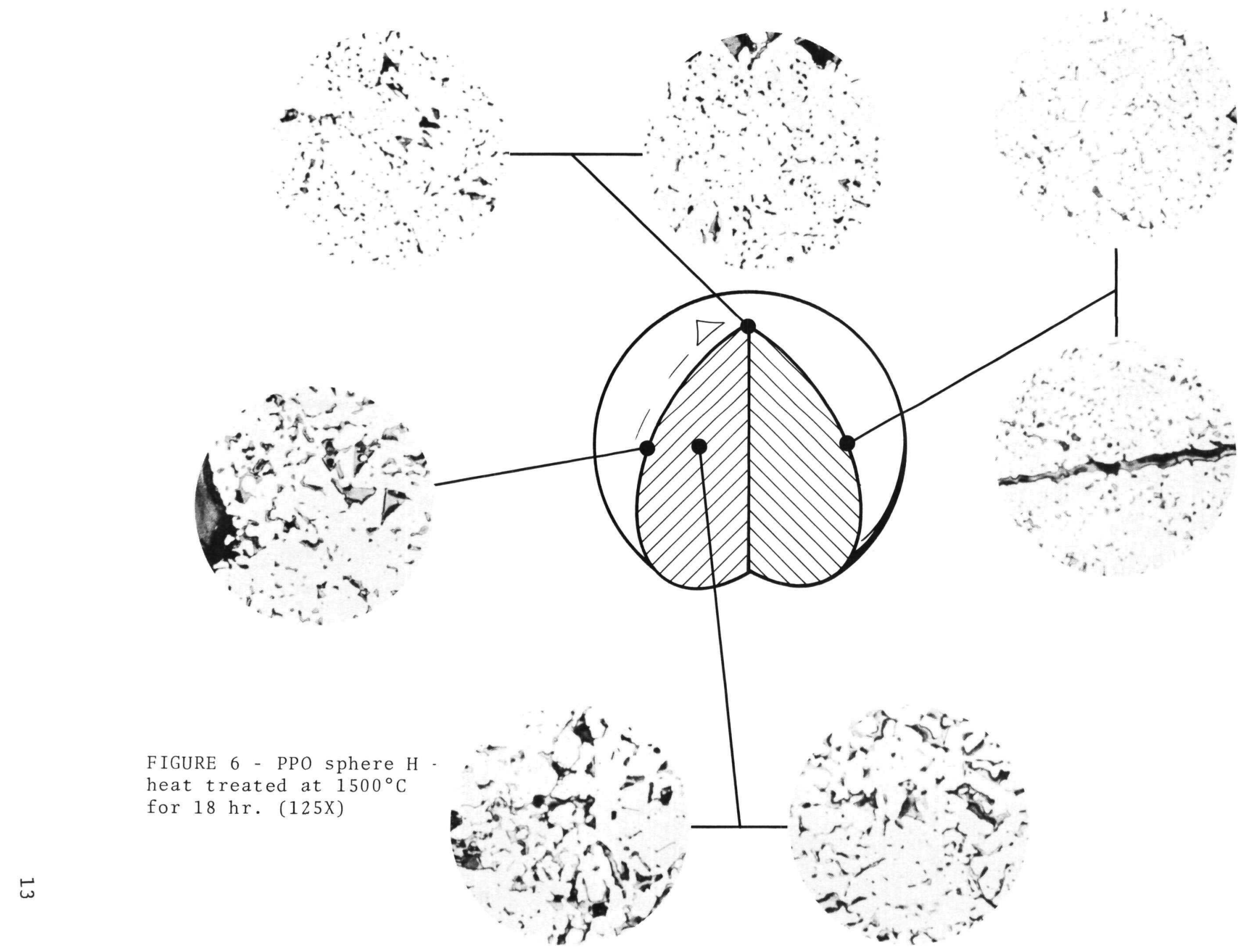


The data presented in Table 1 and Figures 2 through 6 show that the microstructure of PPO spheres is not uniform, at least in the examined spheres. The data do, however, illustrate that thermal stress and shock data calculated assuming the PPO spheres are uniform in cross-section might be somewhat different from the real situation. The fact that interior cracks are already present in the sphere after pressing implies that an analysis of crack propagation and healing is also required to fully characterize the thermal behavior of PPO spheres. It is probably this fact, the presence of small cracks as stress relievers, that allows the PPO sphere to be subjected to fairly rigorous thermal environments without catastropic fracturing. (R. E. Zielinski)

Thermal Stress Analyses Calculations were performed to determine the stresses that appear in MHW PPO spheres due to temperature gradients. Therma1 shock analyses were also performed. These calculations were used to develop the sphere outgassing procedure now being used for MHW PPO spheres.

Thermal Stresses The temperature at every point in a PPO (pressed plutonium oxide) sphexe at a given time is a complex function of the thermal properties of the fuel, the power generation within the fuel, the thermal transfer conditions between the sphere and its environment, and the thermal capacity of its environment. In a PPO sphere, a temperature gradient would be expected to exist along the sphere radius under most conceivable conditions. This situation will result in thermal stresses which are a function of the temperature gradient, the mechanical properties of the fuel, and the geometric properties of the stress field in a sphere.

If we assume that the PPO sphere is a purely elastic body with a uniform cross section and a symmetrical temperature distribution, the thermal stresses can be calculated at any location (Kingery ${ }^{2}$ ).

For the PPO sphere, the center and surface stresses can be expressed as:

$$
\sigma_{t}=\sigma_{r}=\frac{2 E \alpha}{3(1-\nu)}\left(t_{a}-t_{c}\right)
$$

at the center of the sphere, and

$$
\sigma_{t}=\frac{E \alpha}{(1-v)}\left(t_{a}-t_{s}\right), \sigma_{r}=0
$$

at the surface of the sphere, where

$$
\begin{aligned}
\sigma_{t} & =\text { tangential stress } \\
\sigma_{s} & =\text { radial stress } \\
E & =\text { Young modulus } \\
\nu & =\text { Poisson's ratio } \\
\alpha & =\text { thermal expansion coefficient } \\
t_{a} & =\text { effective average temperature } \\
t_{c} & =\text { center temperature } \\
t_{s} & =\text { surface temperature }
\end{aligned}
$$


The values for $E, \alpha$, and $\nu$ are assumed to be independent of temperature. Table 2 lists these thermal stresses for various sphere surface temperatures. This table was developed using the following approximate properties for $\mathrm{PuO}_{2}$ in the temperature range of 300 to $1200^{\circ} \mathrm{C}$.

Shear Modulus, G: $5.9 \times 10^{6} \mathrm{psi}$

Lame's 2 nd Constant, $\lambda: 8.01 \times 10^{6} \mathrm{psi}$

Young Modulus, E: $1.52 \times 10^{7} \mathrm{psi}$

Poisson's Ratio, $\nu: 0.288$

Mean Thermal Expansion Coefficient ${ }^{3}, \alpha: 11.16 \times 10^{-6}{ }^{\circ} \mathrm{C}^{-1}$

Thermal Conductivity, $\mathrm{k}: 6.5 \times 10^{-3} \mathrm{cal} \mathrm{cm}^{-1} \mathrm{sec}^{-1}{ }^{\circ} \mathrm{C}^{-1}$

Density, $\rho: 9.4 \mathrm{~g} / \mathrm{cc}$ ( $82 \%$ of theoretical)

Sphere Radius, $\mathrm{r}: 1.861 \mathrm{~cm}$.

\section{Table 2}

THERMAL STRESS DISTRIBUTION FOR PPO SPHERES WITH SURFACE TEMPERATURES AS STATED

\begin{tabular}{|c|c|c|c|}
\hline $\begin{array}{c}\text { Surface } \\
\text { Temperature } \\
\left({ }^{\circ} \mathrm{C}\right)\end{array}$ & $\begin{array}{c}\text { Center } \\
\text { Temperature } \\
\left({ }^{\circ} \mathrm{C}\right) \\
\end{array}$ & $\begin{array}{c}\text { Surface Stress } \\
\text { (psi) }\end{array}$ & $\begin{array}{c}\text { Center Stress } \\
(\mathrm{ps} \mathbf{i})\end{array}$ \\
\hline 300 & 348 & $\begin{array}{l}\sigma_{t}=3800 \\
\sigma_{r}=0\end{array}$ & $\sigma_{t}=\sigma_{r}=-5700$ \\
\hline 500 & 564 & $\begin{array}{l}\sigma_{t}=5100 \\
\sigma_{t}=0\end{array}$ & $\sigma_{t}=\sigma_{s}=-7600$ \\
\hline 800 & 888 & $\begin{array}{l}\sigma_{t}=7000 \\
\sigma_{s}=0\end{array}$ & $\sigma_{t}=\sigma_{z}=-10500$ \\
\hline 1000 & 1100 & $\begin{array}{l}\sigma_{t}=7950 \\
\sigma_{x}=0\end{array}$ & $\sigma_{t}=\sigma_{z}=-11900$ \\
\hline 1200 & 1302 & $\begin{array}{l}\sigma_{t}=8100 \\
\sigma_{r}=0\end{array}$ & $\sigma_{t}=\sigma_{s}=-12100$ \\
\hline
\end{tabular}

a. Results calculated from Equations (1) and (2).

b. Although E and $\nu$ are somewhat dependent on temperature, these variations were neglected in calculating the stresses given above.

If the maximum tensile stress of $\mathrm{PuO}_{2}$ is assumed to be 7,000 psi, the results 1 isted in Table 2 indicate that thermal cracking of the surface of a PPO sphere may occur with a relatively small radial thermal gradient. The cracks most likely appear as surface microcracks. These cracks may or may not propagate, depending upon the thermal stress resistance of the fue 1. 


\section{Stresses Due to Temperature Changes}

A. Infinite Surface Heat Transfer Coefficient If the coefficient of heat transfer is so large that the surface of the fuel sphere is instantly increased from $t_{0}$ to $t_{1}$, the average temperature of the sphere remains unchanged for a certain time period. During this period, the surface stress, according to Kingery ${ }^{2}$, is:

$$
\sigma=\frac{E \alpha}{1-\nu}\left(t_{0}-t_{1}\right)
$$

where $t_{0}=$ original surface temperature and $t_{1}=$ new surface temperature.

The $\Delta t$ which would produce a stress equivalent to the breaking strength can be expressed as:

$$
\Delta t=t_{0}-t_{1}=\frac{S_{t}(1-v)}{E \alpha}
$$

where $S_{t}$ is the maximum tensile stress.

When the sphere is cooled, the surface is immediately in tension and fracture should occur instantaneously at $\mathrm{T}$ (time) $=0$. When the sphere is heated, the surface is in compression and it is possible for fracture to occur due to the center tensile stress or due to the shearing stresses which are half of the principal stresses:

$$
\tau=\frac{E \alpha}{2(1-v)}\left(t_{0}-t_{1}\right)
$$

where $\tau=$ shear stress.

The temperature difference to develop this stress is:

$$
\Delta t=t_{0}-t_{1}=\frac{2 \tau(1-v)}{E \alpha} .
$$

If the shear stress is low, it is possible for fracture to still occur as a result of the center tensile stress exceeding the fracture strength. For this condition, the temperature difference is:

$$
\Delta t=t_{0}-t_{1}=\frac{2 S_{t}(1-\nu)}{0.771 E \alpha}
$$

and the time to fracture after the application of an instantaneous temperature change to the surface can be expressed as:

$$
T=\frac{0.0574 r^{2}}{a},
$$

where a = thermal diffusivity of the fuel.

Application of this analysis to a ppo sphere indicates that during heating, an instantaneous temperature change of $76^{\circ} \mathrm{C}$ on the surface of the sphere would cause it to fracture in $20 \mathrm{sec}$, assuming a thermal diffusivity of $9.95 \times 10^{-3} \mathrm{~cm}^{2} \mathrm{sec}^{-1}$. 
B. Finite Surface Heat Transfer Coefficient The above equations assume an infinitely large surface heat transfer coefficient and, thus, apply only to instantaneous changes of the surface temperature. If surface heat transfer is considered to occur at a finite rate, the maximum $\Delta t$ to which the sphere can be exposed to on heating or cooling according to Crandall and $\mathrm{Ging}^{4}$ is:

$$
\Delta t=\left[\frac{S_{t}(1-\nu)}{E \alpha}\right]\left[2.5+\frac{5.0}{\beta}\right]
$$

where $\beta=r h / k=r H$ is Biot's modulus and $r$ is the sphere radius. $H$ is the surface heat transfer coefficient defined as $H=h / k$ where $h$ is the heat transfer coefficient and $k$ is the thermal conductivity of the solid. This equation is valid for the heating and cooling of a sphere if $0.1 \leq$ $\beta \leq 10$. This range of $\beta$ will probably be appropriate to heat transfer conditions suitable to processing of PPO spheres. This expression is related to the maximum thermal flux which a sphere can endure without fracturing under a prescribed set of boundary conditions for the surface of the sphere. The difficulty with using expression (9), aside from the fact that the correct values for $E, S_{t}, v$, and $\alpha$ depend on the actual temperature of the sphere at fracture, is that $h$ is dependent on the surface properties of the sphere as well as the thermal conductivity of the fuel. Therefore, while values can be assumed for the various terms in the equation to provide $\Delta t$ values, experimentally determined values of $\mathrm{H}$ and the mechanical properties are required for quantitative application of expression (9). To illustrate the use of expression (9), the thermal shock that will lead to sphere fracture can be estimated as follows:

Using $S_{t} \simeq 7000$ psi and a value of $\beta=1$, the maximum $\Delta t$ to which a PPO sphere can be safely exposed is approximately $220^{\circ} \mathrm{C}$. A value of $\beta=1$ is equivalent to $\mathrm{h}=3.49 \times 10^{-3} \mathrm{cal} \mathrm{cm}^{-2} \mathrm{sec}^{-1} \mathrm{C}^{-1}$ for $\mathrm{PuO}_{2}$ in the temperature range of interest $\left(300-1200^{\circ} \mathrm{C}\right)$.

C. Constant Rate of Change of Sphere Surface Temperature If the surface temperature of the sphere is varied linearly with time, two expressions can be derived to describe the maximum acceptable heating and cooling rates for the sphere. These expressions were derived using the assumption that, for the case of a sphere with a constant surface temperature change rate $\theta\left({ }^{\circ} \mathrm{C} \mathrm{sec}-1\right)$, the difference between the center and surface temperature is given approximately by: ${ }^{2}$

$$
t_{c}-t_{s}=\frac{\theta r^{2}}{5 a}
$$

where $r=$ sphere radius and

$a=$ thermal diffusivity of the sphere material.

Making the worst case assumption, that $t_{2}$ in expression (1) is approximately equal to $t_{s}$ and that $t_{\text {an }}$ in expression (2) is approximately equal to $t_{c}$, two expressions were derived for the maximum heating and cooling rates for a sphere that will not induce cracking. For heating a sphere, the approximate maximum heating rate is given by

$$
\theta_{H}=\left[\frac{a S_{t}(1-\nu)}{E \alpha}\right]\left[\frac{7}{r^{2}}\right]
$$


and for cooling by

$$
\theta_{c}=\left[\frac{a S_{t}(1-v)}{E \alpha}\right]\left[\frac{5}{r^{2}}\right]
$$

Since the values for $t_{\mathrm{a}}$ in (1) and (2) are very close to the arithmetic average of $t_{c}$ and $t_{s}$, the maximum allowable rates are essentially twice those calculated from (10b) and (11). Substitution of appropriate property values for $\mathrm{PuO}_{2}$ into (10b) and (11) for the 300 to $1200^{\circ} \mathrm{C}$ temperature range yields an average heating rate of about $35^{\circ} \mathrm{C} \mathrm{min}^{-1}$ and an average cooling rate of about $25^{\circ} \mathrm{C} \mathrm{min}-1$. These data indicate that if fuel spheres are to maintain their integrity, controlled heating and cooling cycles are required whenever the fuel spheres are to be heat treated.

The results of this study indicate that a controlled thermal environment for a PPO sphere is mandatory to prevent failure due to thermal shock. Consistent with this study, the following controlled heating and cooling cycle was recommended for the $1500^{\circ} \mathrm{C}$, 1-hr outgassing process for development and production spheres:

1. Ambient to $800^{\circ} \mathrm{C}$ in approximate $1 \mathrm{y} 10 \mathrm{~min}$.

2. 800 to $1100^{\circ} \mathrm{C}$ at $25^{\circ} \mathrm{C} / \mathrm{min}$.

3. Hold at $1100^{\circ} \mathrm{C}$ for $15-20 \mathrm{~min}$.

4. 1100 to $1500^{\circ} \mathrm{C}$ at $25^{\circ} \mathrm{C} / \mathrm{min}$.

5. Hold at $1500^{\circ} \mathrm{C}$ for $60 \mathrm{~min}$.

6. 1500 to $700^{\circ} \mathrm{C}$ at $15^{\circ} \mathrm{C} / \mathrm{min}$.

7. At $700^{\circ} \mathrm{C}$, the furnace is slowly backfilled with argon. The sphere is not removed from the furnace until further cooling becomes negligible or for a minimum of $15 \mathrm{~min}$.

The third step in this procedure (hold at $1100^{\circ} \mathrm{C}$ for $15-20$ min) was incorporated to allow helium to be released from the sphere so that minimal internal helium pressure is present when the sphere is heated to the higher temperature. This step should be sufficient for newly pressed spheres. The effect of long-term helium generation has not been considered for this procedure; however, a PPO sphere aged for approximately 19 months at storage temperatures was outgassed using this procedure and, although several hair-line cracks appeared after outgassing, the sphere did not fracture. These data indicate that minor changes in the outgassing procedures might be necessary for aged spheres to protect their structural integrity; however, more helium release data on PPO spheres are required before the procedures will be modified to accommodate aged spheres.

This outgassing procedure is based upon calculated values which have not yet been supported by sufficient experimental evidence; however, several normal development spheres have already been processed using the above outgassing procedure and none of these exhibited any evidence of fracturing. 
Limitations The above calculations were performed with the basic assumption that PPO spheres are consistently uniform. This implies that they have a very uniform microstructure consisting of: 1) uniform grain size and 2) uniform porosity distribution and shape (spherical, isolated pores). It also implies that the thermal and mechanical properties of the spheres are symmetrical; this means that the spheres have no hot spots or localized stress risers which would be the result of abnormal grain growth or density gradients.

An important factor not considered in the thermal analys is calculations is the influence of helium generated in the sphere on the mechanical integrity of the sphere. It is likely that if PPO spheres are stored at 1 ow temperatures (approximate $1 y 300^{\circ} \mathrm{C}$ ) for 1 ong periods of time, they will build up helium inventories. When these spheres are thermally treated, the amount of their helium inventories and the mechanisms by which these inventories are released might affect the structural integrity of the spheres even though a controlled heating and cooling rate is followed.

An experiment performed to determine the thermal shock behavior of a sphere would have to be treated with respect to helium release also. This should not be a serious problem for newly prepared spheres, but it can be for spheres that are aged at low temperatures for long periods of time.

This analysis was concerned with stoichiometric spheres heated to a maximum temperature of $1500^{\circ} \mathrm{C}$. The fracture of substoichiometric spheres may well depend on $\mathrm{O} / \mathrm{Pu}$ ratio, the mechanical properties of the second phase, and the microstructural changes induced by the formation of the second phase.

Also a sphere that has been reduced to $\mathrm{PuO}_{2-\mathrm{x}}$ and re-oxidized may have thermal and mechanical properties different from spheres that are maintained at $\mathrm{PuO}_{2}$ or $\mathrm{PuO}_{2-\mathrm{x}}$, and the behavior of such spheres could not be predicted from the above data because the effect of the re-oxidation on their mechanical and thermal properties would have to be experimentally determined since they are presently unknown. (R. E. Zielinski and $\mathrm{V}$. J. Tennery)

\section{Appendix}

Effect of New Experimenta1 Data on Calculations New experimenta1 data made available by Los Alamos Scientific Laboratory ${ }^{5}$ has established measured values for the temperature gradients across MHW PPO spheres. These data were factored into the thermal stress analyses and the results are presented. The values of the temperature gradients used in the calculations were those measured during the cooling of the ppo sphere after sintering had taken place.

A. Center and Surface Stresses These stresses were calculated using Equations 1 and 2. The new values are 1 isted in Table 3 . These data indicate that thermal stresses are much greater at the lower temperature where the greatest thermal gradients exist. 
Table 3

THERMAL STRESS DISTRIBUTION FOR PPO SPHERES WITH SURFACE TEMPERATURES AS STATED

$\begin{array}{cc}\begin{array}{c}\text { Surface } \\ \text { Temperature } \\ \left({ }^{\circ} \mathrm{C}\right)\end{array} & \begin{array}{c}\text { Center } \\ \text { Temperature } \\ 400\end{array} \\ \frac{\left({ }^{\circ} \mathrm{C}\right)}{500} & 643 \\ 800 & 695 \\ 1000 & 905 \\ 1200 & 1080 \\ & 1270\end{array}$

\begin{tabular}{|c|c|c|c|}
\hline \multicolumn{2}{|c|}{$\begin{array}{c}\text { Surface Stress } \\
\text { (psi) } \\
\end{array}$} & \multicolumn{2}{|c|}{$\begin{array}{c}\text { Center Stress } \\
\text { (psi) }\end{array}$} \\
\hline $\begin{array}{l}\sigma t \\
\sigma r\end{array}$ & $\begin{array}{l}=19,398 \\
=0\end{array}$ & $\sigma t=\sigma r$ & $=-18,768$ \\
\hline $\begin{array}{l}\sigma t \\
\sigma r\end{array}$ & $\begin{array}{l}=19,291 \\
=0\end{array}$ & $\sigma t=\sigma r$ & $=-13,232$ \\
\hline $\begin{array}{l}\sigma t \\
\sigma r\end{array}$ & $\begin{array}{l}=12,396 \\
=0\end{array}$ & $\sigma t=\sigma r$ & $=-6,681$ \\
\hline $\begin{array}{l}\sigma t \\
\sigma r\end{array}$ & $\begin{array}{l}=9,293 \\
=0\end{array}$ & $\sigma t=\sigma r$ & $=-5,592$ \\
\hline $\begin{array}{l}\sigma t \\
\sigma r\end{array}$ & $\begin{array}{l}=8,715 \\
=0\end{array}$ & $\sigma t=\sigma r$ & $=-5,187$ \\
\hline
\end{tabular}

Since the thermal profile across a PPO sphere is different from calculated values, thermal conductivity and diffusivity values determined for ${ }^{2}{ }^{39} \mathrm{PuO}_{2}$ can no longer be applied to ${ }^{238} \mathrm{PuO}_{2}$, and until values are available, a complete thermal stress analysis cannot be performed.

It is interesting to note, however, that the present sphere outgassing procedure calculated using the properties of ${ }^{239} \mathrm{PuO}_{2}$ has been successful. Until further experimentally determined values for ${ }^{23}{ }^{8} \mathrm{PuO}_{2}$ become available, the present procedure will be continued. As these additional data become available from LASL, they should immediately be factored into the thermal analyses of the sphere so that the best possible handling and heat treatment procedures are developed. (R. E. Zielinski)

A Quadrupole Mass Spectrometer Capable of Evolved Gas Analysis of $\mathrm{PuO}_{2}$ Up to $1850^{\circ} \mathrm{C}$ The use of production quantities of $\mathrm{PuO}_{2}$ for heat source applications has led to the need for continued study of the characteristics of this material, not only as a final product, but also at every step in the process.

One of the most desired analyses is that of evolved gas as a function of temperature. This need has resulted in the installation of a quadrupole mass spectrometer with these capabilities.

The apparatus consists of a detector located outside an alpha glovebox with a $3 / 4$ in. line connecting it to the sample within the box. This line incorporates an absolute filter which should maintain the detector and associated vacuum system free from radioactive contamination. The sample tube, located inside a furnace chamber, can be program heated to $1850^{\circ} \mathrm{C}$. The sample vacuum system is independent of the furnace system, thus eliminating any contribution of evolved gas from the furnace. 
The quadrupole mass spectrometer has the potential of detecting masses up to $600 \mathrm{amu}$; however, the installation geometry severely limits this capability to elements and compounds of relatively high vapor pressure. This limitation is a result of the gas path and the temperature of the tube between the sample and the detector, which allow high temperature volatiles to condense before they reach the detector. Heating the tube to temperatures above $200^{\circ} \mathrm{C}$ is impractical with this design. The apparatus has been checked out at temperatures up to $1850^{\circ} \mathrm{C}$. At very high sensitivity, background masses 16, 17, 18, 28, 40, and 44 are apparent at both ambient and $1850^{\circ} \mathrm{C}$. Attempts were made to determine the detection sensitivity of various gases. A standard helium leak of $3 \times 10^{-8}$ $\mathrm{cc} / \mathrm{sec}$ was detectable under dynamic pumping conditions. Other gases were introduced by means of a micrometer valve. This technique was only moderately successful, since control between $10^{-10}$ and $10^{-6} \mathrm{cc} / \mathrm{sec}$ was not precise; however, it appeared, after repeated determinations, that $10^{-8} \mathrm{cc} / \mathrm{sec}$ range of $\mathrm{O}_{2}, \mathrm{H}_{2}$, and $\mathrm{Ar}$ could be detected with the ion pump operating.

A gas mixture of $\mathrm{H}_{2}, \mathrm{HD}$, and $\mathrm{D}_{2}$ was introduced into the connection tube at $10^{-4}$ torr and subsequently leaked into the detector by valve control. The chamber pressure was maintained at $10^{-5}$ torr by controlling the amount of sample leaking into the detector. It is necessary to maintain a pressure below $10^{-4}$ torr for detector operation. The results exhibited we11 defined peaks at 2, 3, and 4 amu. Other materials such as $\mathrm{MgH}_{2}$ and $\mathrm{Ag}_{2} \mathrm{O}$ have been heated and successfully examined for decomposition of $\mathrm{H}_{2}$ and $\mathrm{O}_{2}$ respectively. The apparatus as it stands presently is a qualitative tool; however, it can be made quantitative after extensive calibration.

Cold check-out of this system is essentially completed: Glovebox hood fronts are being installed and leak checked. The systems should, thus, be ready for handling plutonium-238 samples short1y. (D. E. Etter)

Plutonium in Environmental Waters With the advent of electrical energy generation by nuclear means, a problem which may arise is "how much plutonium may dissolve in natural waters, and what form might this plutonium assume?" Natural waters are usually only mildly acidic or mildly alkaline, so the answer to this question may not be a simple extrapolation of the familiar chemistry of plutonium in acid solutions near pH O. For example, it is sometimes alleged that in solutions at $\mathrm{pH}$ values of 6 or greater, the hydrolysis of the tetravalent plutonium cation, $\mathrm{Pu}^{4+}$, is so extensive that the system is stabilized and other plutonium species, such as $\mathrm{PuO}_{2}^{+}$, would be rendered unimportant.

Let it be supposed that a sample of plutonium in water of $\mathrm{pH} 6$ is in equilibrium with typical hydrous plutonium oxides which might form at this $\mathrm{pH}$ value: for example, $\mathrm{Pu}(\mathrm{OH})_{4}$ or $\mathrm{PuO}_{2}(\mathrm{OH})_{2}$, or both of these hydrous oxides together. If only $\mathrm{Pu}(\mathrm{OH})_{4}$ is present, then the concentration of $\mathrm{Pu}^{4+}$ in equilibrium with this hydrous oxide may be determined from the solubility product of this hydrous oxide of about $10^{-55}$

$$
\left[\mathrm{Pu}^{4+}\right]\left[\mathrm{OH}^{-}\right]^{4}=10^{-55}
$$

or $\left[\mathrm{Pu}^{4+}\right]=10^{-23} \mathrm{M}$, a very small value indeed. Now, if equilibrium prevails in this solution, then the oxidation-reduction equilibrium which prevails may be stated as in Equation (2): 


$$
E=1.1702+0.05916 \log \frac{\left[\mathrm{PuO}_{2}^{+}\right]\left[\mathrm{H}^{+}\right]^{4}}{\left[\mathrm{Pu}^{4+}\right]}
$$

But the value of each term in Equation (2) is known except for $E$, the prevailing potential value, and $\left[\mathrm{PuO}_{2}^{+}\right]$, the concentration of pentavalent plutonium. Hence, by assuming some values for $E$, the concentration of [PuO ${ }_{2}^{+}$may be calculated. Such calculation is shown as line A in Figure 7. In the event that only $\mathrm{PuO}_{2}(\mathrm{OH})_{2}$ is present in the solution, then equilibrium may also be expressed as in Equation (3):

$$
\mathrm{E}=0.9164+0.05916 \log \frac{\left[\mathrm{PuO}_{2}^{2}\right]}{\left[\mathrm{PuO}_{2}^{+}\right]}
$$

where $\left[\mathrm{PuO}_{2}^{2+}\right]$ has the value $10^{-7} \mathrm{M}$ at $\mathrm{pH}$ 6. A plot of Equation (3) is shown as line $B$ in Figure 7. Where lines $A$ and $B$ intersect, at a potential of about $0.807 \mathrm{~V}$, both $\mathrm{Pu}(\mathrm{OH})_{4}$ and $\mathrm{PuO}_{2}(\mathrm{OH})_{2}$ are present together. This potential value agrees with the value predicted from Equation (4) at $\mathrm{pH}$ 6:

$$
\mathrm{E}=1.0433+0.02958 \log \frac{\left[\mathrm{PuO}_{2}^{2+}\right]\left[\mathrm{H}^{+}\right]^{4}}{\left[\mathrm{Pu}^{4+}\right]} .
$$

Hence, based upon this simple calculation, the concentration of pentavalent plutonium at $\mathrm{pH} 6$ may have a value of almost $10^{-5} \mathrm{M}$. As this concentration of pentavalent plutonium alone far exceeds the radiological control guide (RCG) for natural waters, perhaps it should not be immediately assumed that, at $\mathrm{pH}$, tetravalent plutonium hydroxide stabilizes the system and renders al1 other species unimportant. Of course, it may be argued that a potential of $0.8 \mathrm{~V}$ is most unlikely in natural waters. It may also be argued that natural waters might contain materials capable of complexing pentavalent plutonium. Both of these arguments have some merit. Their effect, however, is to counteract one another;

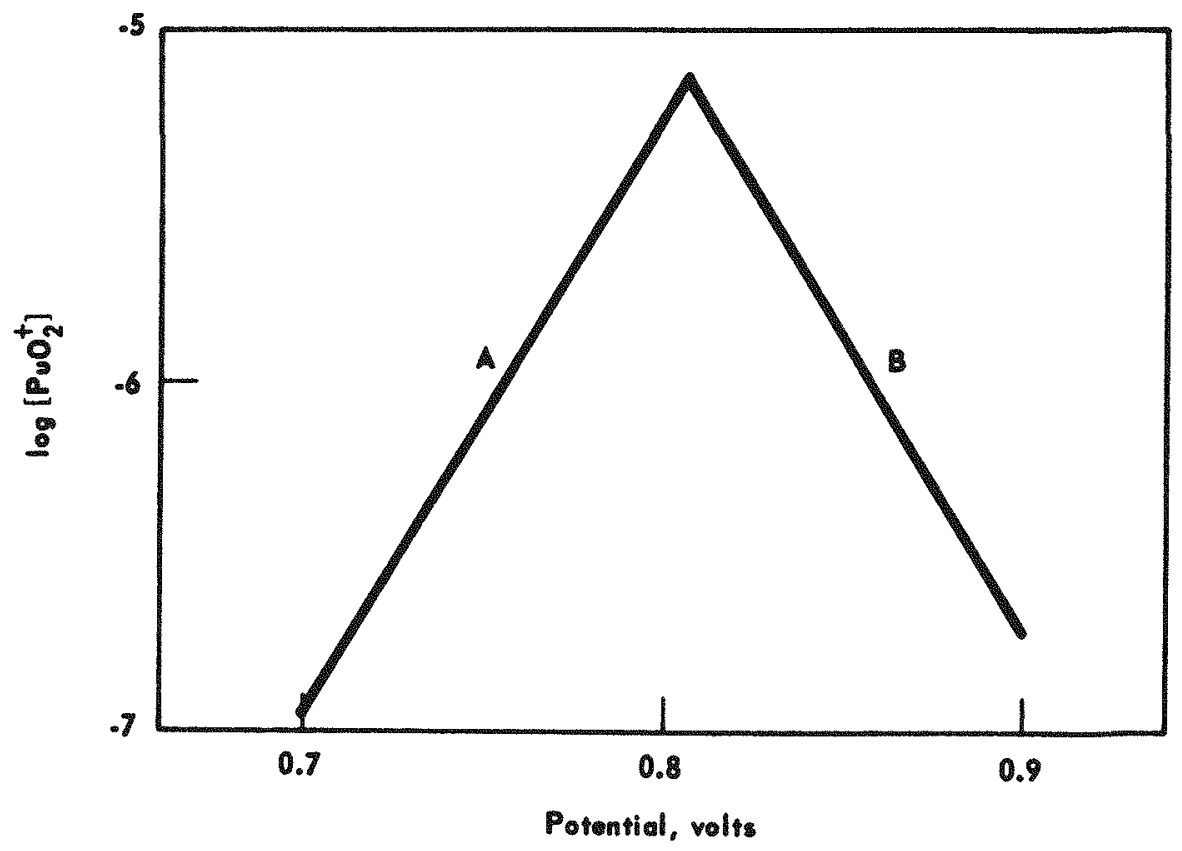

FIGURE 7 - Maximum permissible concentration of pentavalent plutonium at $\mathrm{pH} 6$ as a function of solution potential (vs. N. H. E.). Complexation of plutonium ions has been neglected. 
while lower potentials, such as probably characterize natural water, may act to decrease the concentration of pentavalent plutonium perhaps to levels within the RCG, so may complexation act to increase the concentration of pentavalent plutonium as well as other plutonium oxidation states. (G. L. Silver) 


\title{
Capsule Materials
}

\author{
EXAMINATION OF IRIDIUM HEMISHELLS
}

To better identify the nature of the iridium being used in the Multihundred Watt Heat Source Program, random samples were examined using the quadrupole mass spectrometer and both scanning and transmission microscopy. The material used in these studies was ORNL iridium of both high and low levels of tungsten impurity. The samples used for the studies were electron discharge machined from hemishells that had been hydroformed at Mound Laboratory.

Mass Spectrometer Study The quadrupole mass spectrometer study was designed to determine whether oxygen off-gassing from iridium could be determined using available mass spectrometric equipment and normal techniques.

A sample was electron discharge machined from a hemishell that was in the wrought condition as hydroformed. The material had a $3000 \mathrm{ppm}$ tungsten impurity level. The iridium sample was heated in vacuum by R.F. coupling and the oxygen off-gassing was monitored as a function of temperature.

The greatest increase in oxygen off-gassing occurred when the sample was heated from ambient to $940^{\circ} \mathrm{C}$. This was probably oxygen desorption from the surface. The off-gassing of oxygen continued as the temperature was increased to $1210^{\circ} \mathrm{C}$, although the intensity was less than $5 \%$ of the maximum detected at the lower temperatures as determined by peak height analysis at the same system pressure.

There was no further oxygen off-gassing until the sample temperature was $1500^{\circ} \mathrm{C}$, then a slight off-gassing of oxygen was noticed. The off-gassing quickly reduced to background and no additional off-gassing occurred up to the maximum test temperature of $1600^{\circ} \mathrm{C}$.

System pressure during the test was maintained at $2 \times 10^{-6}$ torr or lower. The oxygen off-gassing was monitored by scanning the increased intensities of the mass 16 and 32 peaks during the experiment. No effort was made to obtain a total mass scan, although intermittent scans were made for iridium oxide during the course of the experiment. The oxide, however, was never observed.

No attempt was made to quantitize the oxygen off-gassing since the experiment was primarily one to determine whether such a study could be 
made using available equipment. Some system modifications will have to be made if additional studies of this nature are required; however, even the present experimental set-up was sufficient to determine the offgassing of oxygen from metal surfaces.

The results of the study indicate that adsorbed oxygen is present on the surface of iridium hemishells. This oxygen is apparently removed in vacuum at temperatures less than $1210^{\circ} \mathrm{C}$. The oxygen off-gassing at $1500^{\circ} \mathrm{C}$ is difficult to explain on the basis of this one experiment since iridium oxide was not observed and no attempt was made to scan for other metallic oxides. Perhaps, the system pressure was too high to observe iridium oxide.

The fact that the system pressure did not increase noticeably during the test indicates that if there are other surface contaminants present they are not very significant. If other studies of this nature are to be performed, an attempt will be made to significantly reduce the operating system pressure.

Transmission Electron Microscopy

Samples of two iridium hemishells were examined for substructure details using the transmission electron microscope. Both samples were from hemishells prepared from ORNL-supplied iridium. They both had $3000 \mathrm{ppm}$ of tungsten as an impurity. One of the samples was from a hemishell in the wrought condition, and the other was from a hemishell that was recrystallized and annealed at $1500^{\circ} \mathrm{C}$.

The sample of the wrought iridium exhibited sub cells and dislocation networks; the annealed specimens showed rather clean grains with only few random dislocations present. One peculiarity noted in both specimens was that at magnifications greater than $125,000 \mathrm{X}$ a series of black spots became visible in some areas of the samples. These spots appeared in a somewhat regular array and gave the appearance of solid material. Since they were not visible at the lower magnifications, they could not be identified by $x$-ray diffraction; however, they might be compared to the surface oxide that sometimes develops on poorly prepared refractory metal samples, although they were significantly smaller in size. They did not change appearance when the beam was focused on them and their number did not seem to increase during the sample examination. For all practical purposes they could probably be identified as some sort of oxide contaminant.

No other extraordinary features were observed in either sample.

Scanning Electron Microscopy

Scanning electron microscopy (SEM) was used to examine the surface

features of four hemishells. A11 four were hydroformed from ORNL-supplied iridium. One sample (EBP-18-3) contained $300 \mathrm{ppm}$ tungsten impurity and the others (WC-8-2-1, WC-8-1, and WC-5-2) contained $3000 \mathrm{ppm}$ tungsten impurity. One sample was unique in that two hemishells were welded together: WC-8-1, a wrought hemishe11, and WC-5-2, a hemishel1 that was recrystalized for 1 hr at $1050^{\circ} \mathrm{C}$.

Sample EBP-18-3 was dye penetrant checked and gave a number of indications. The surface was then cleaned prior to SEM examination using the normal cleaning procedure. 
Figure 8 shows a typical area of the surface. Arrow A shows one of the adhesion layers of iridium that were deposited on this region of the surface during the grinding operation. Arrow B shows a unique feature of a series of scalloped layers. This probably occurred during the hydroforming operation. As the material was shaped a surface layer of metal seems to have pulled away from the parent material. This type of feature has not been observed in earlier surface studies. It is possible, however, that this type of feature has been present but was destroyed during grinding and lapping operations. These scalloped layers were missed during the grinding operation; however, if it was ground down, an adhesion layer would probably be the result of the operation. Arrow $C$ points to a depression that is partially covered by an adhesion layer.

Figure 9 shows the area surrounding the depression in greater detail. This photograph shows that there are minor cracks in the parent surface of the iridium and these cracks run perpendicular to the grinding direction. The depression, itself, seems to be filled with some particulate matter. This material seems to be randomly distributed on the entire surface (arrows). This material is probably the dispersion particles of the dye penetrant developer which were not cleaned away. This developer has calcium carbonate and silica as the dispersion particles.

Figure 10 and 11 are high magnification photographs of the depression and scalloped layers shown in Figure 8. It seems possible that both of these features can give dye penetrant indications since developer particles seemed to be concentrated in both areas.

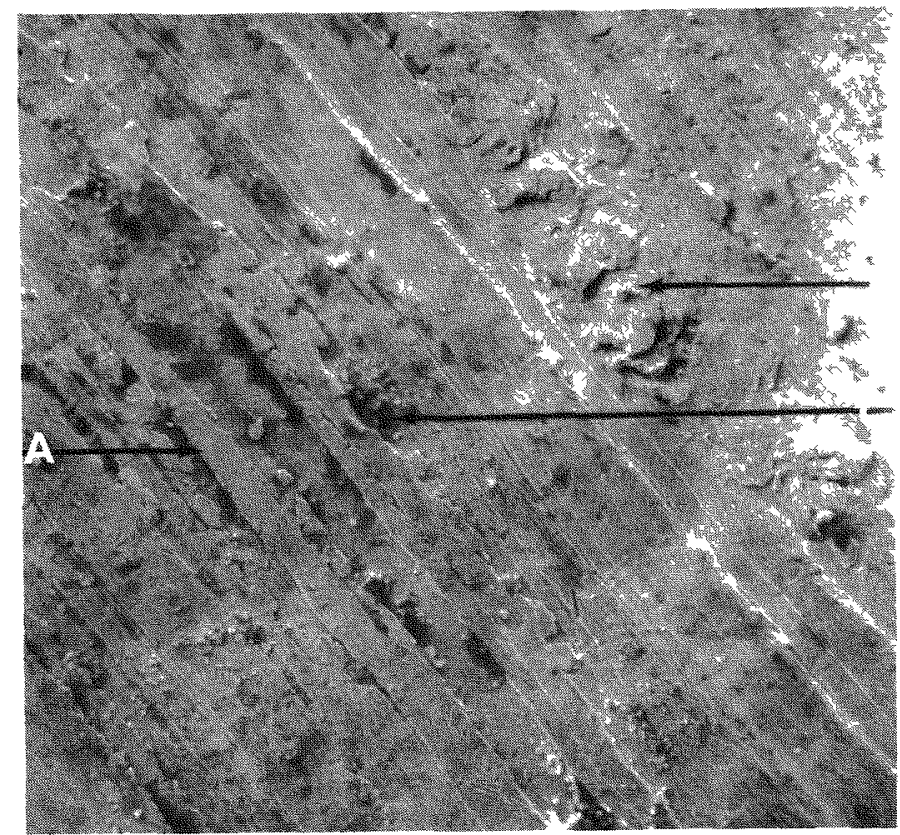

FIGURE 8 - Surface of iridium hemishe11 EBP-18-3 (730X). 


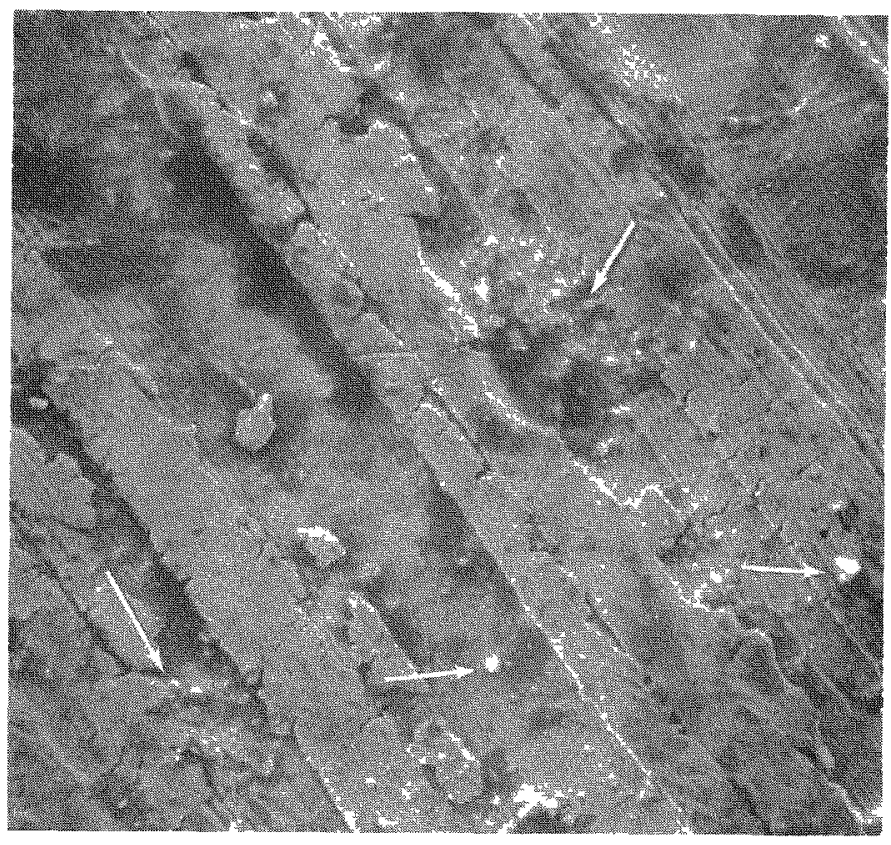

FIGURE 9 - Adhesion layers on surface of EBP-18-3 (1730X).

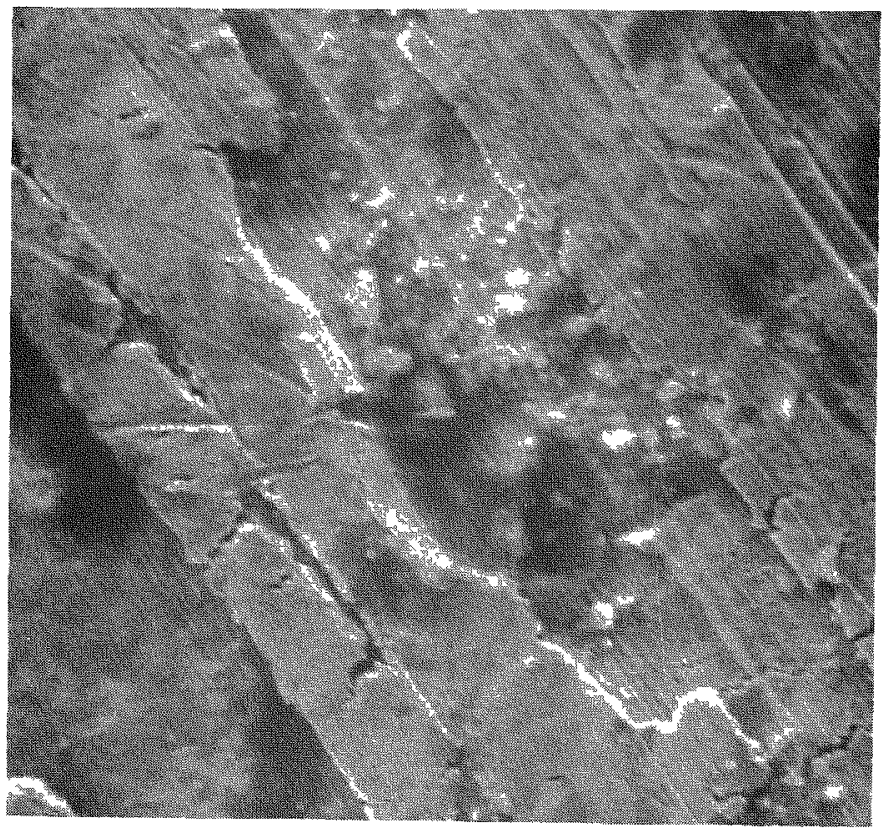

FIGURE 10 - Depression in surface of EBP-18-3 (4000X). 


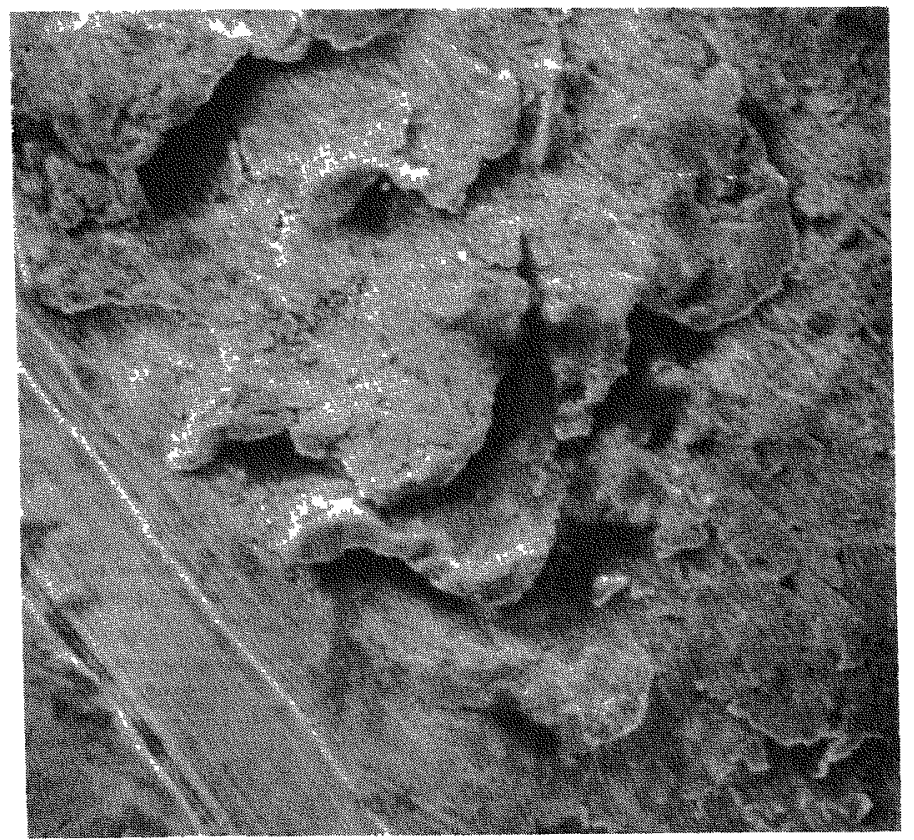

FIGURE 11 - Layer affect on surface of EBP-18-3 (4000X).

Figures 12 and 13 are photographs of an accumulation of the particles that are distributed on the sample. They seemed to be concentrated in a gouged out depression.

Figure 14 is a photograph of what appears to be a cubic crystal that adhered to the surface after the grinding operation. The face of the crystal has an edge approximately $4.76 \mu \mathrm{m}$ long. Since the SEM is not presently equipped with an $x$-ray analysis system, the crystal could not be identified.

Sample WC-8-2-1 also had several dye penetrant indications prior to SEM examination. This sample was cleaned only with acetone prior to examination.

Figure 15 shows one of the poorest areas of this sample. The minute cracks run longitudinally in the specimen and this is one of the most concentrated areas of these cracks which in reality are very minute. The surface of the specimen is quite a bit smoother than that of EBP-18-3. There do not appear to be any adhesion layers present in the sample. The area in the upper left of the photograph is shown in greater detail in Figure 16.

In Figure 16, a depression is shown. The depression is filled with dye penetrant developer. The amount of developer present is much greater than the amount that normally remains after cleaning as evidenced by the examination of the previous sample. The depression seems to have been 


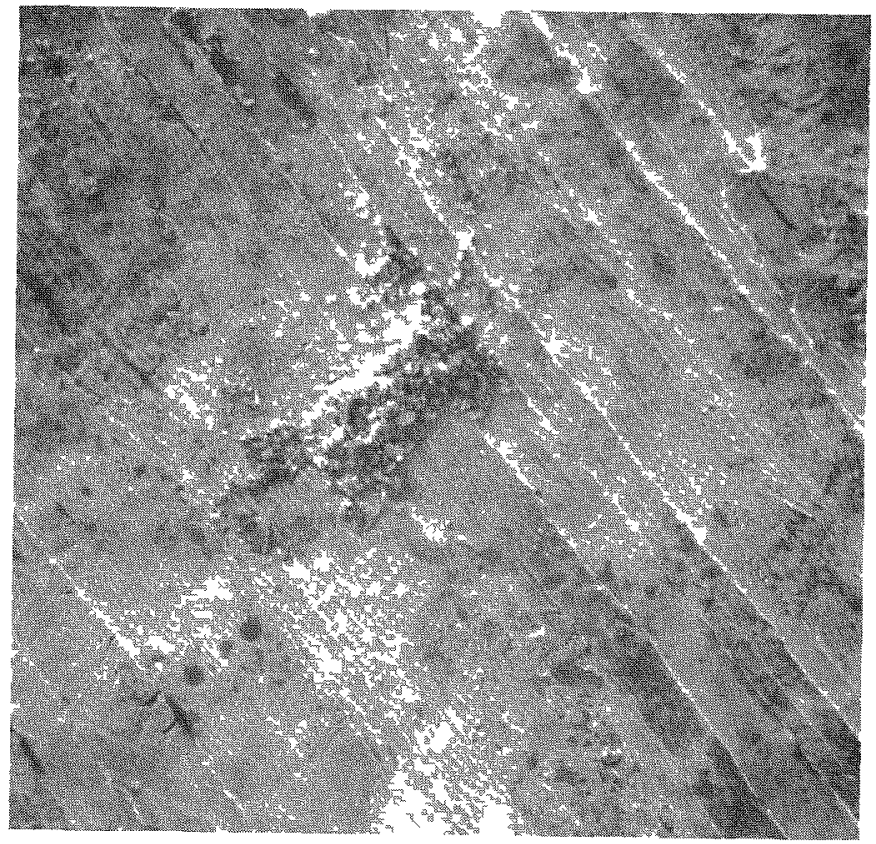

FIGURE 12 - Particle agglomeration on surface of EBP-18-3 (720X).

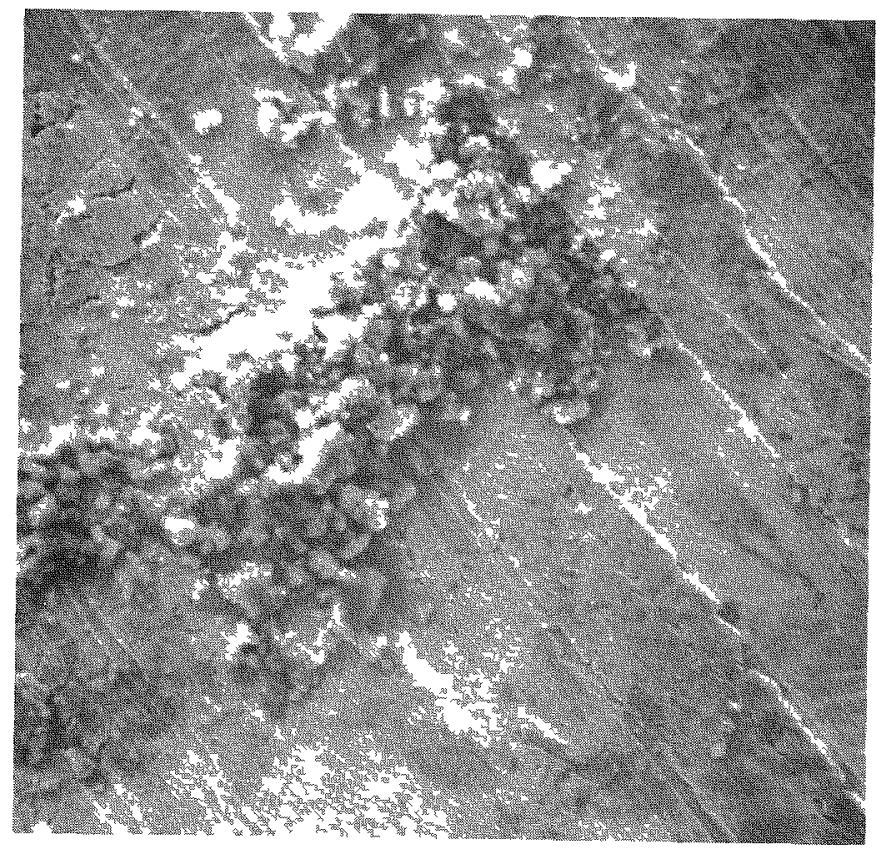

FIGURE 13 - Particle agglomeration on surface of EBP-18-3 (1730X). 


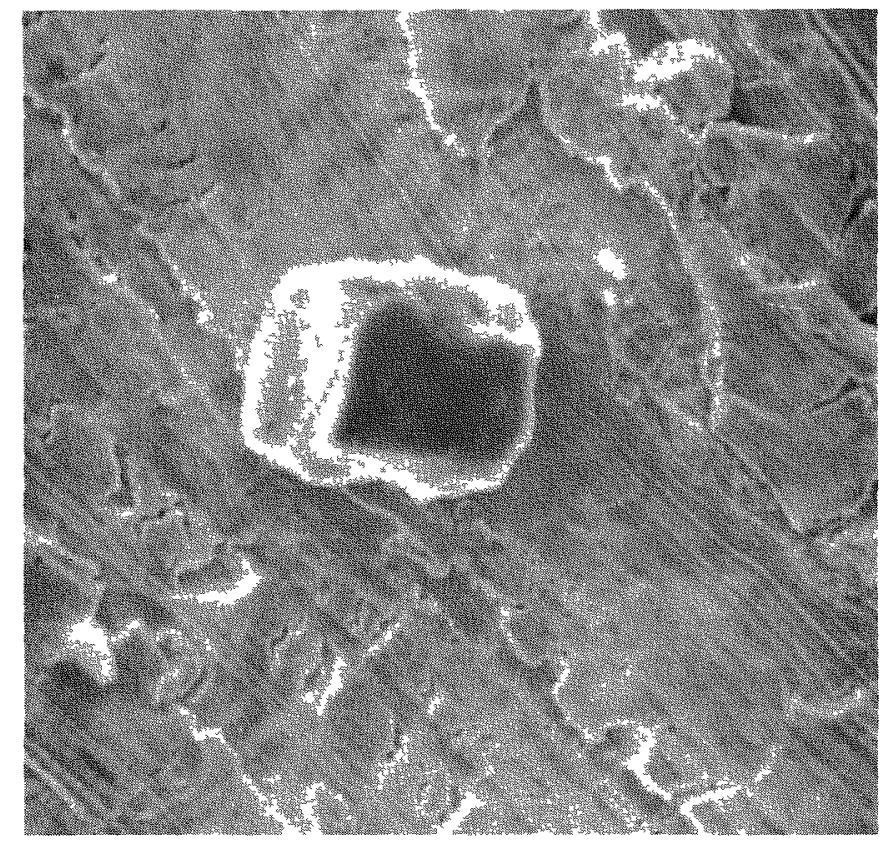

FIGURE 14 - Crystal observed on surface of EBP-18-3 (4000X).

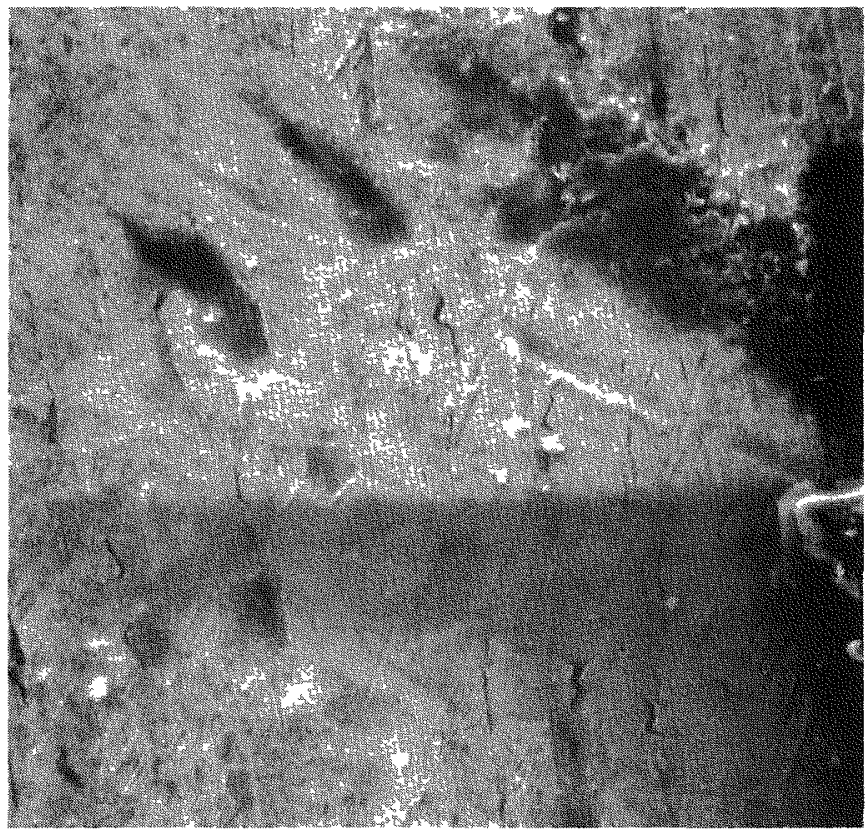

FIGURE 15 - Surface of hemishel1 WC-8-2-1 (1060X). 


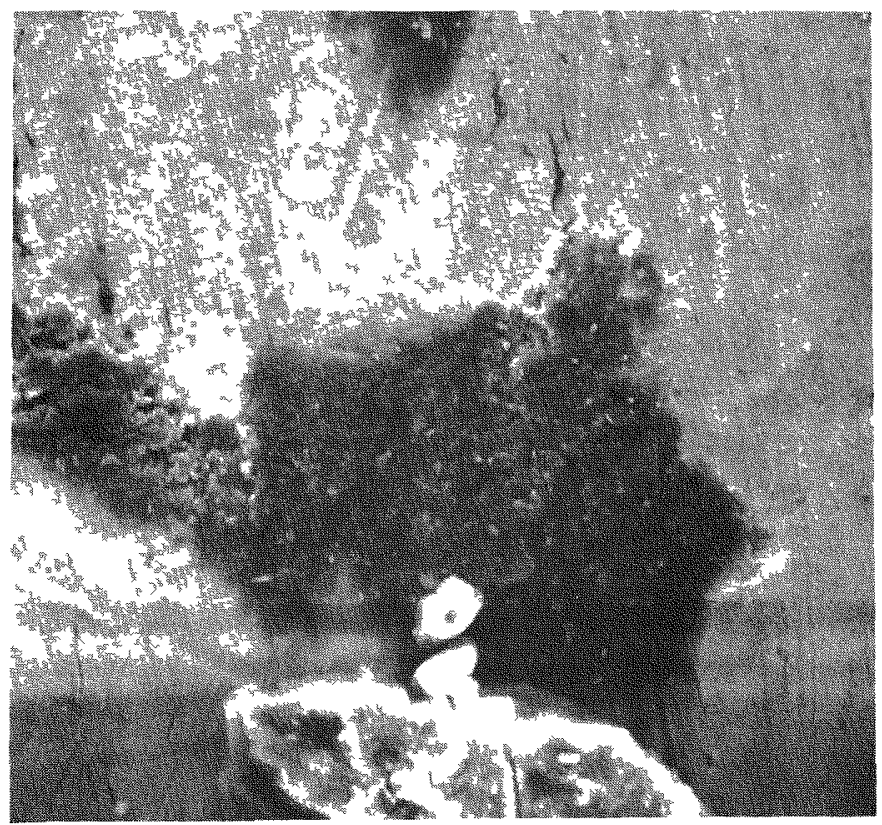

FIGURE 16 - Depression on surface of WC-8-2-1 (1060X).

caused by a pop-off of a plece of the surface. The solid particle at the bottom of the depression appears to be an organic contaminant because of the charging effects. Figure 17 shows this particle in greater detail and now it appears to be a metallic piece with an organic coating on the surface. The metallic piece could be the pop-off from the depression, and the organic material could be the carrier for the dispersion particles of the dye penetrant developer. The metallic piece has a defined thickness as shown by the arrows.

The surface of sample WC-8-1 is shown in Figure 18. This surface is very smooth and only a few minor imperfections are present. Some very sma11 surface depressions (the largest being $2.2 \mu \mathrm{m}$ in length) are present. Most of these imperfections are aligned in the longitudinal direction and might be the result of the forming operation. There were no defects observed that would yield dye penetrant indications. The line running diagonally across the bottom of the photograph is a scratch mark which would not affect the integrity of the material.

Figure 19 shows a higher magnification photograph of the surface. The surface irregularıties, in the boxed-in area, are typical of those present on the surface. Figure 20 shows a photograph of the irregularities at approximately $4000 \mathrm{x}$. If this is compared to Figures 10 and 11 , the difference in the surfaces of the two types of iridium material become readily apparent. 


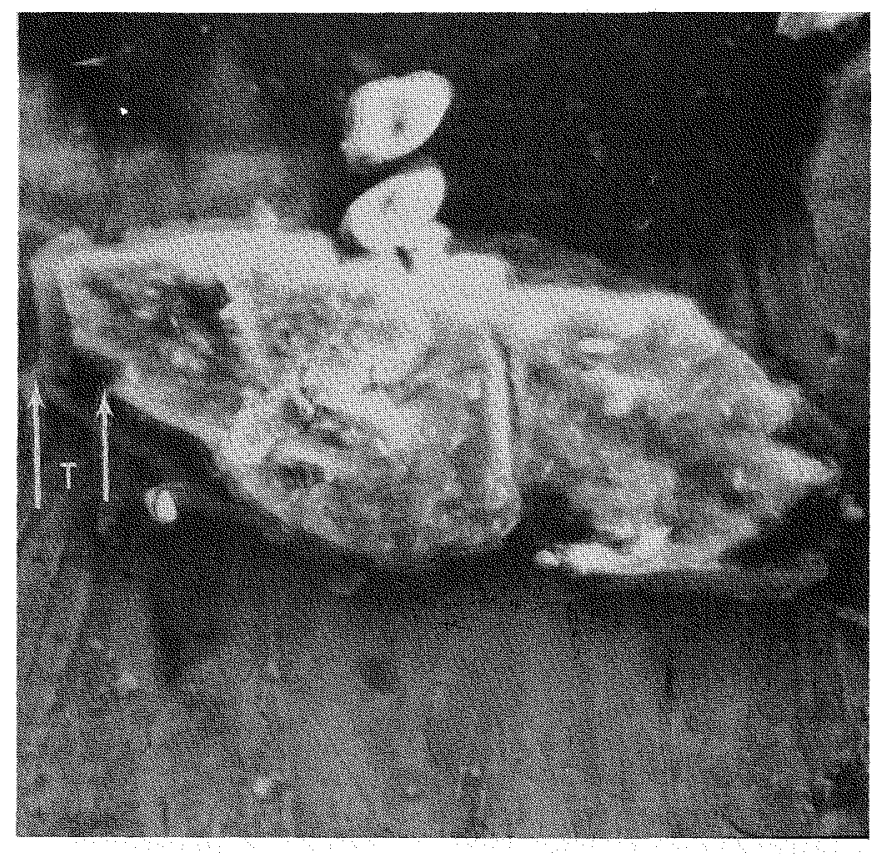

FIGURE 17 - Metallic piece found lying on surface of WC-8-2-1 (1700X).

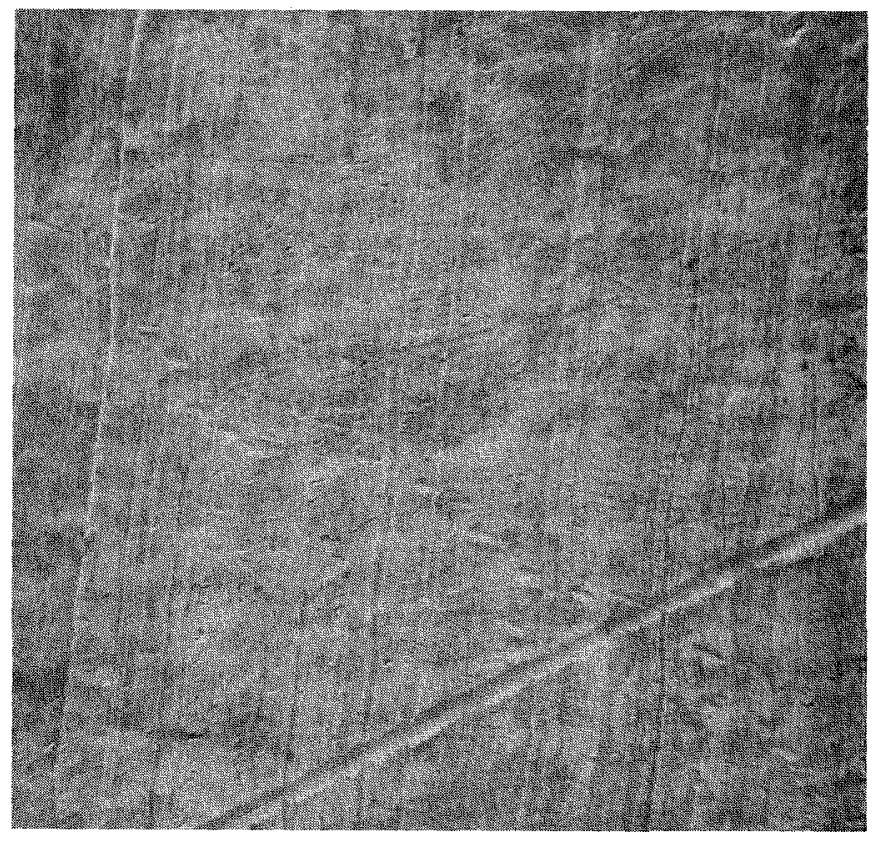

FIGURE 18 - Surface of iridium hemishell WC-8-1 (710X) 


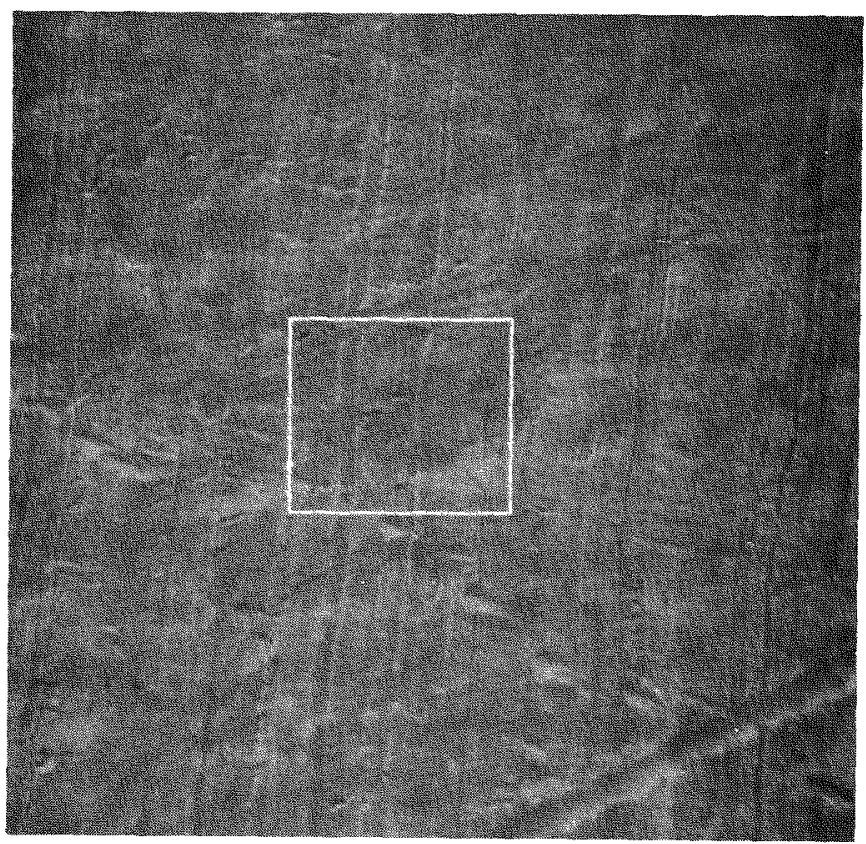

FIGURE 19 - Surface of Irıdıum hemıshe11 WC-8-1 (1010X).

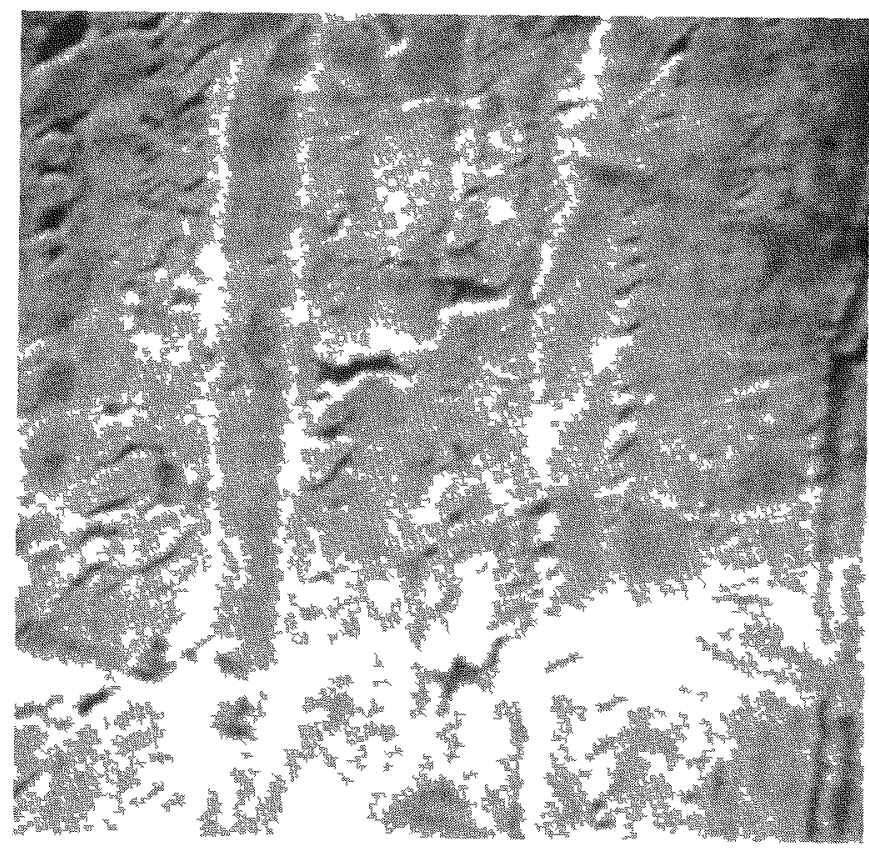

FIGURE 20 - Surface of Iridium hemishel1 WC-8-1 (4060X). 
Figure 21 shows the weld zone joining WC-8-1 to WC-5-2. The recrysta1lized structure and the weld direction (arrow A) can be readily distinguished. Arrows $B$ and $C$ point to metallic particles that were frozen in the weld zone. Part of the weld zone (arrow D) is in relief. Why this occurred is not known.

Figure 22 shows the grain relief in greater detail. Also shown is a stain. The origin of the stain is not known but it does not appear to be harmful. This part, however, is being subjected to a cleaning process and will be examined later to see if the stains are cleaned up. Near the frozen metal on the top of the photograph is what appears to be a crack. Figure 23, however, shows that this is a stain. The stain is more intense than the one shown in Figure 22. A great deal of grain relief is observed in this photograph. The grains seem to have this staining effect extending beneath them. This could indicate that perhaps some impurity in the parent material is being released during the welding operation or some liquid can get into the grain relief and is then forced out and results in a stain. The dark streaks in this photograph are from the shadow of the metal piece that has been frozen in the weld zone. This sample will be re-examined after cleaning to see if the stains are removed.

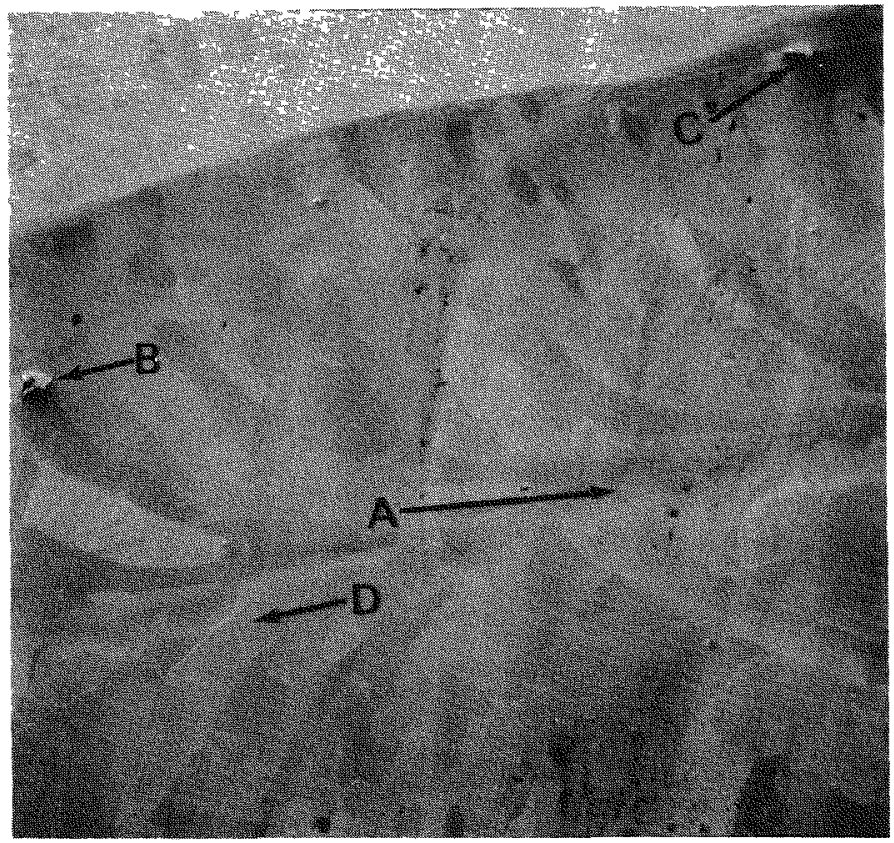

FIGURE 21 - We1d zone of WC-8-1 and WC-5-2 (41X). 


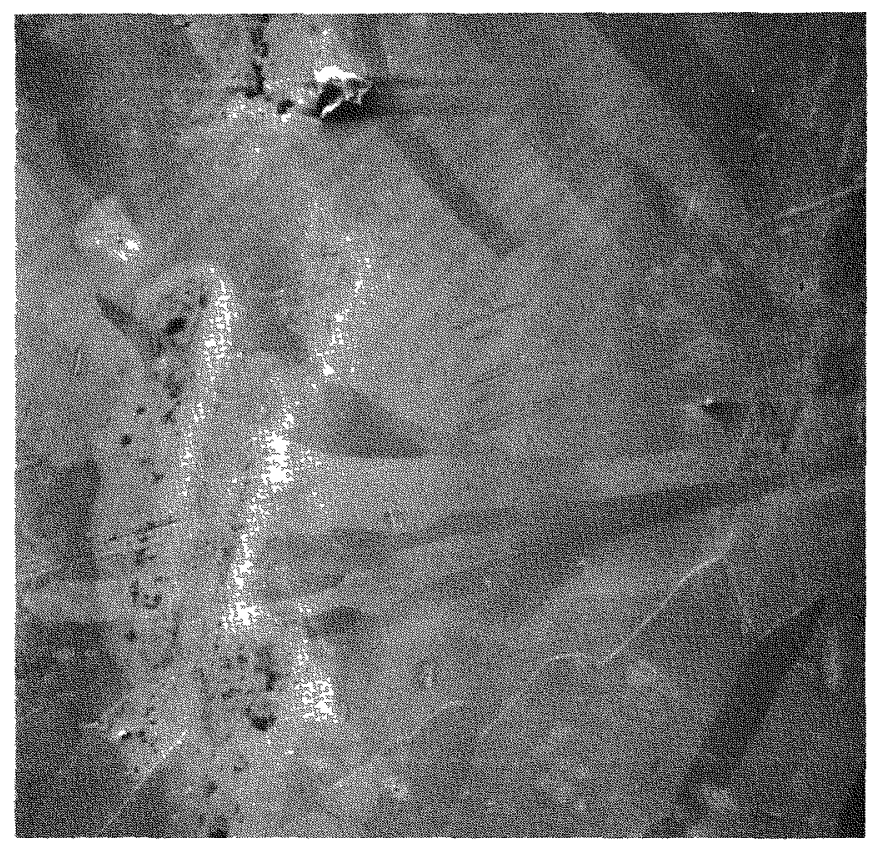

FIGURE 22 - Grain relief in the weld zone (73X).

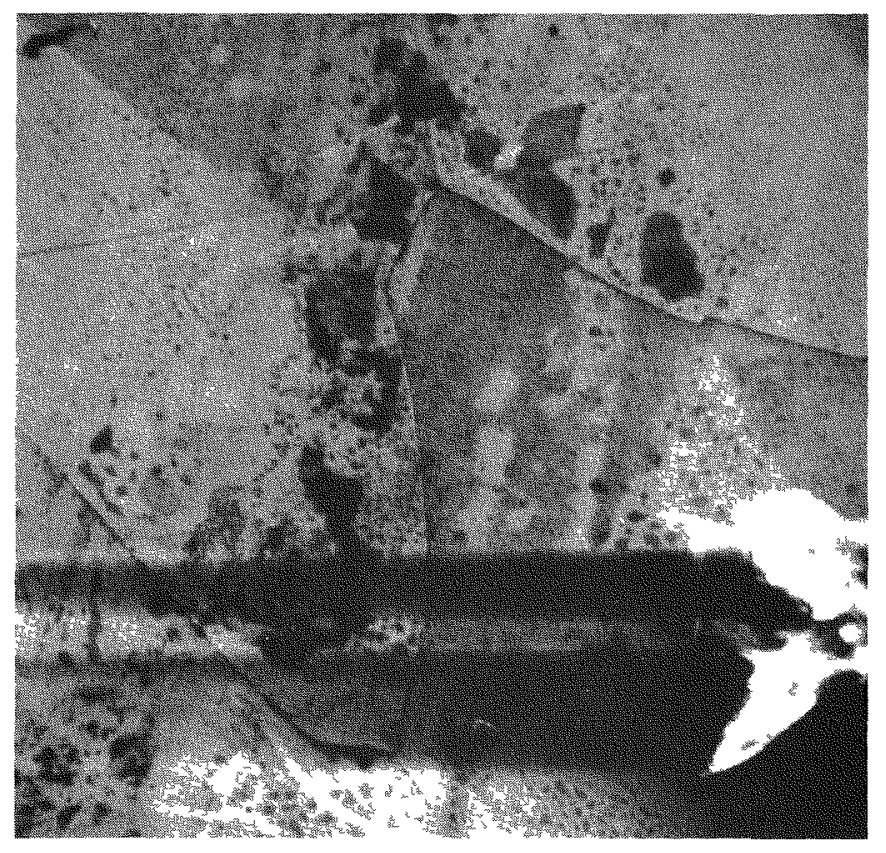

FIGURE 23 - Grain relief and staining in the weld zone (403X). 
Figure 24 shows the surface of WC-5-2. Many surface scratches are present on this hemishe11, but again they have not affected the integrity of the hemishell. The surfaces of the recrystallized grains are very obvious in this sample. The black spots present on the surface seem to be spherical pores. Figure 25, however, shows that some of the spots are surface contaminants, and the others with the lighting effect around them are pores. These pores seem to be aligned longitudinally again and seem more spherical than those observed in WC-8-1. This rounding effect could be the result of the recrystallization treatment. Since the pores are aligned as in the other hemishells that were examined, they are probably the result of the effects of the forming operation on the iridium surface.

Figure 26 shows the pores in greater detail. The lighting effect on the perimeter is due to reflectance of the edge of the pore. Figure 27 shows the pores in greater detail and Figure 28 is a derivative (first) photograph of the area shown in Figure 27. This photograph confirms the fact that the objects of interest are pores or depressions since they stand out in relief in this photograph. This photograph also indicates that they are not very deep and should not affect the integrity of the hemishe11.

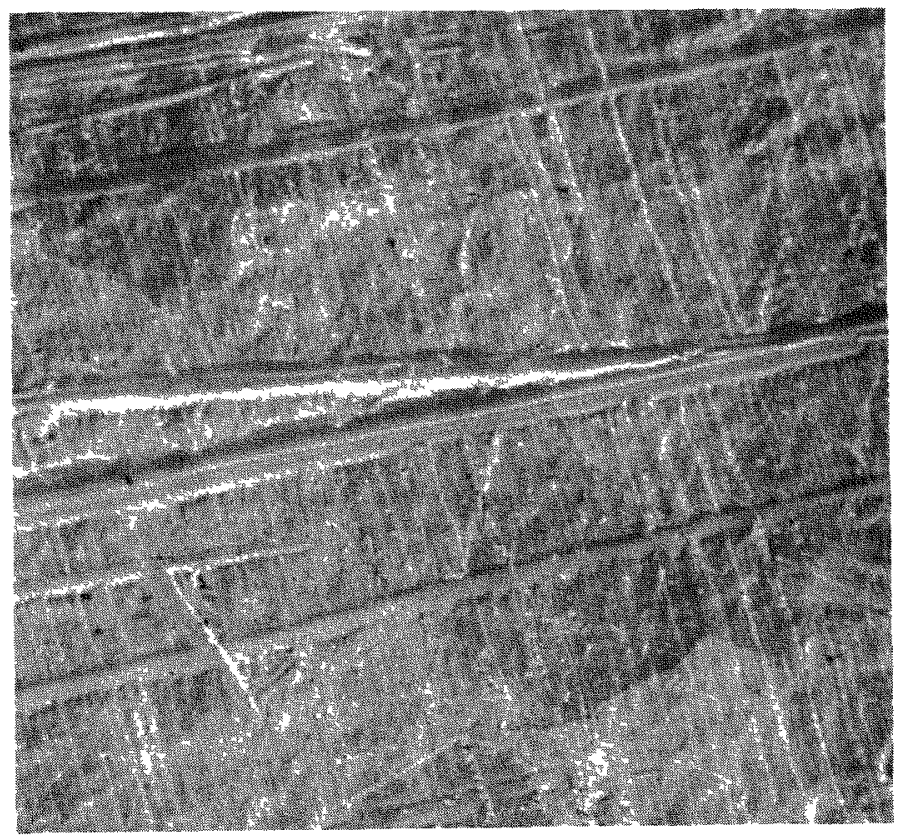

Figure 24 - Surface of iridium hemishell WC-5-2 (430X). 


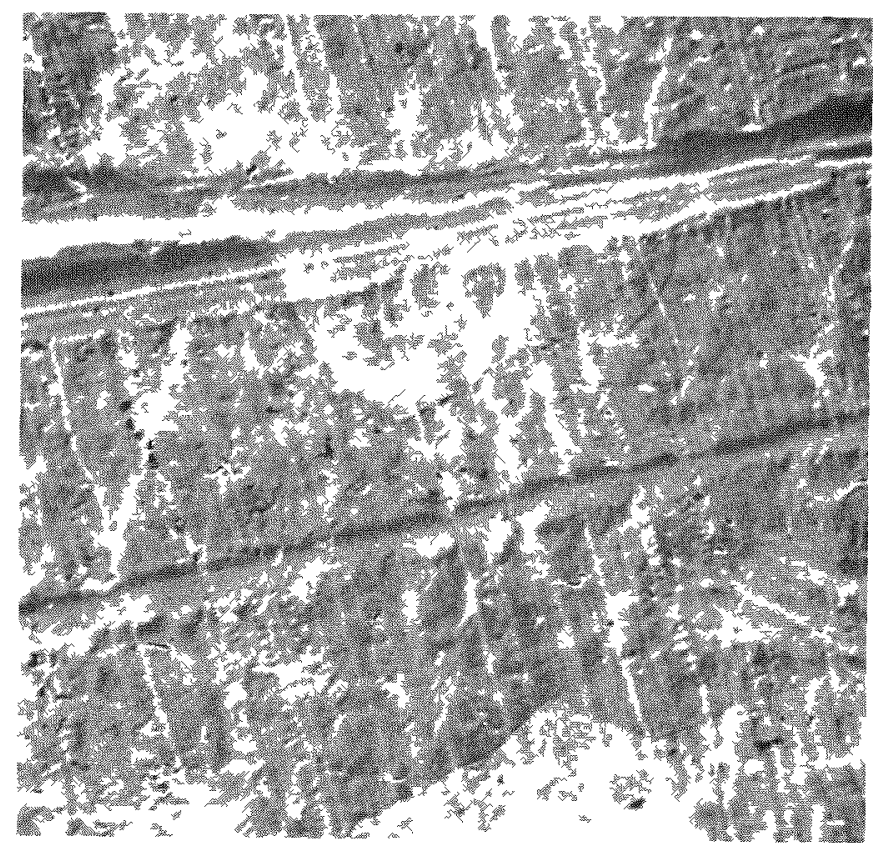

FIGURE 25 - Surface of iridium hemishe11 WC-5-2 (700X).

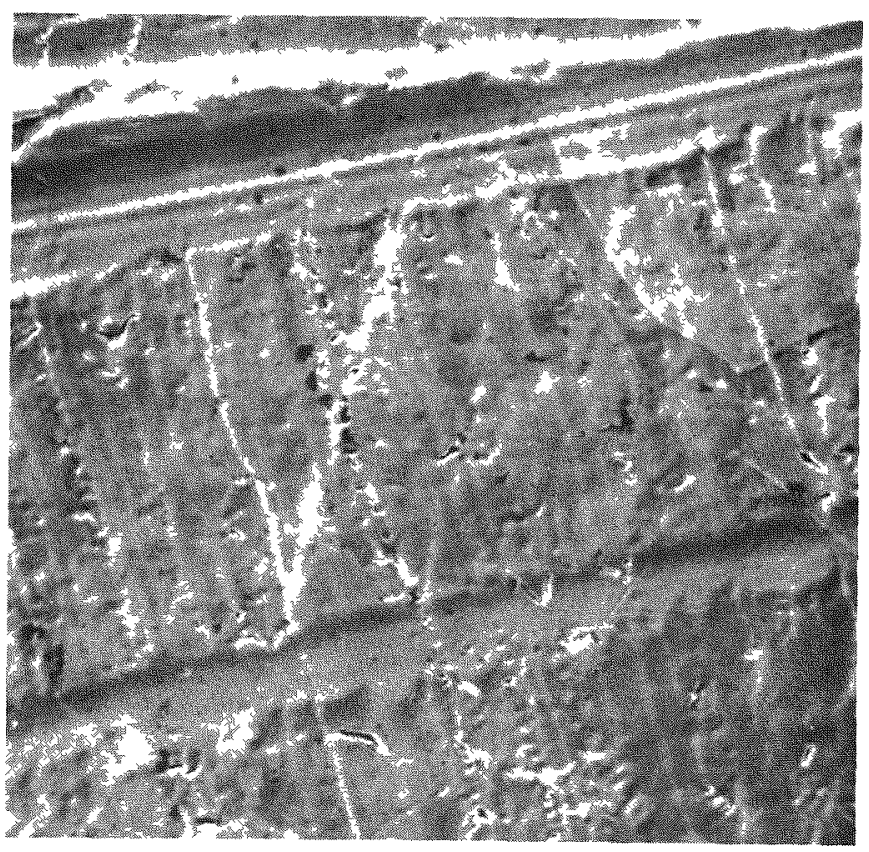

FIGURE 26 - Surface of iridium hemishe11 WC-5-2 (1040X). 


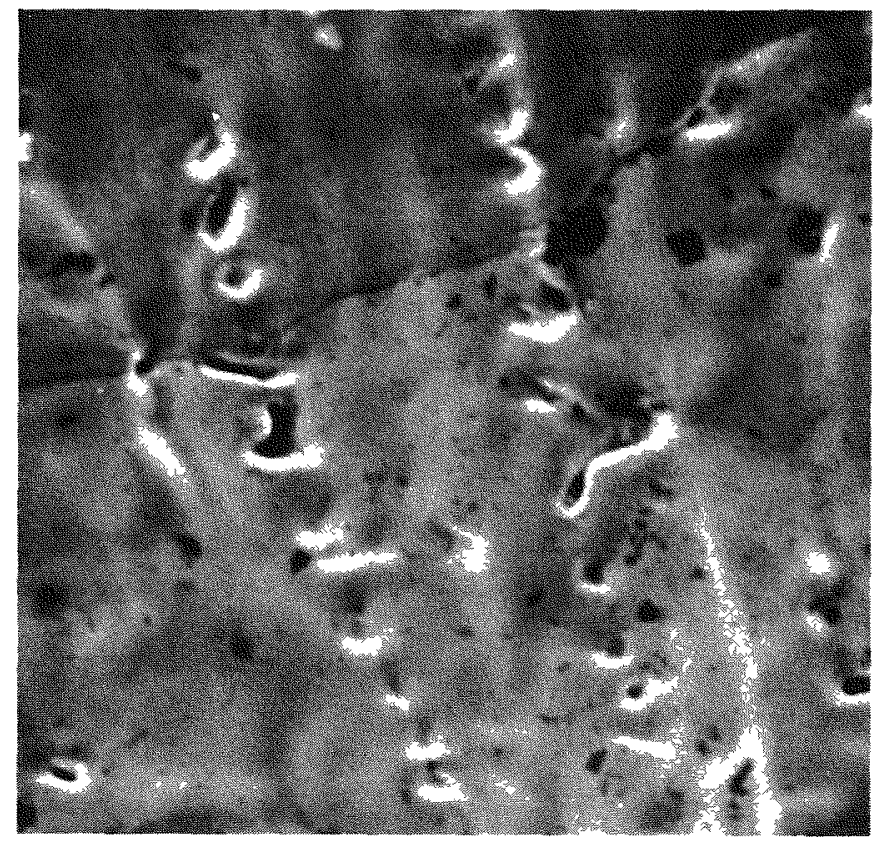

FIGURE 27 - Pores located on the surface of WC-5-2 (4040X).

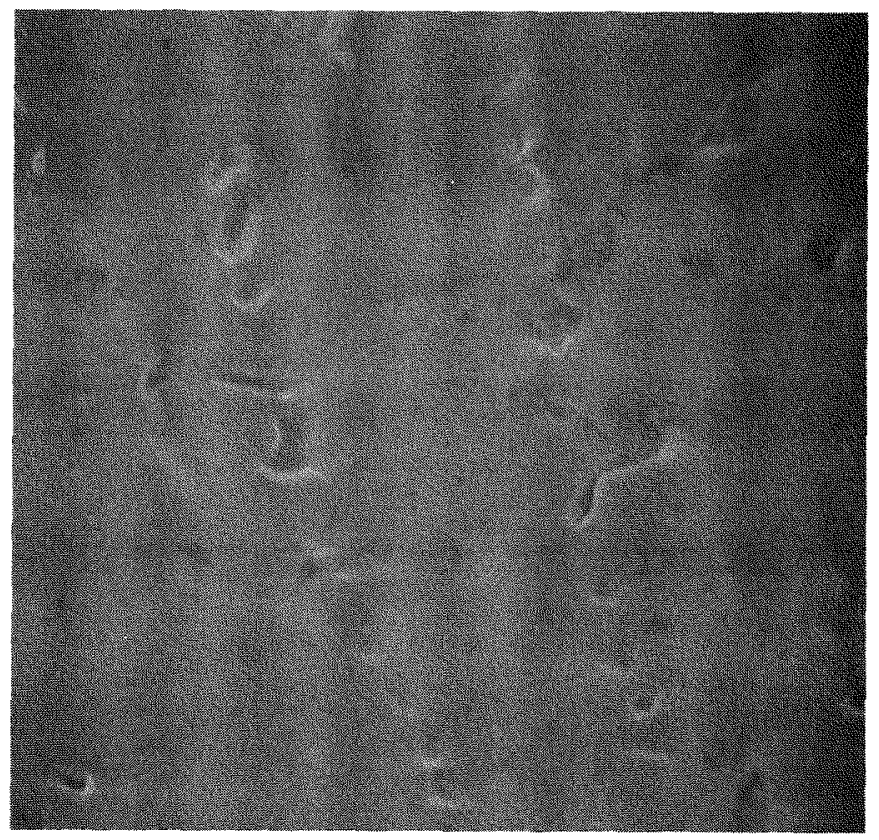

FIGURE 28 - First derivative photograph of field shown in Figure 20 (4040X). 
The SEM examination showed that hemishells hydroformed from iridium containing $3000 \mathrm{ppm}$ tungsten impurity possess a much smoother and uniform surface. Recrystallization of the hemishell rounds out the surface pores which seem to be a result of the hydroforming process because of their alignment on the surface. These pores are present only in the iridium containing $3000 \mathrm{ppm}$ tungsten impurity. The iridium hemishell with 300 ppm tungsten impurity has more severe scalloped layer defects aligned on the surface.

The discovery of the dye penetrant developer particles on the surface of the hemishe11s that have been so checked resulted in a revision of the cleaning process. Hemishells cleaned using the new method have not yet been examined to determine the effectiveness of the method.

The stain in the weld zone, as well as the degree of grain relief, was surprising. The cause of the staining is not known but once the sample is cleaned, it will be re-examined to see if the stains are easily and efficiently removed. Why the grain relief occurs is not known at the present time.

Future work will be performed to determine the effectiveness of new cleaning procedures, to determine the cause and effect of the stains in the weld zone, and to examine the general nature of the surfaces of test hemishe11s. (R. E. Zielinski) 


\section{References}

1. R. E. Zielinski and V. J. Tennery, "Thermal Stress Analyses," this report, pp. 14-19.

2. W. D. Kingery, "Factors Affecting Thermal Stress Resistance of Ceramic Materia1s," J. Amer. Ceram. Soc., 38, (1), 3-15 (1955).

3. T. K. Kennan et a1., Data Sheets for PPO Radioisotopic Fue1, LA-5160-MS, Los Alamos Scientific Laboratory, Los Alamos, New Mexico (February 1973).

4. W. B. Crandall and J. Ging, "Thermal Shock Analysis of Spherical Shapes," J.Amer. Ceram. Soc., 38, (1), 44-54 (1955).

5. T. K. Keenan, LASL, Private Communication. 